\title{
Enduring Memory Impairment in Monkeys after Ischemic Damage to the Hippocampus
}

\author{
Stuart Zola-Morgan,, ${ }^{1,2}$ Larry R. Squire, ${ }^{1,2}$ Nancy L. Rempel, ${ }^{3}$ Robert P. Clower, ${ }^{2}$ and David G. Amaral ${ }^{3,4}$ \\ 'Veterans Affairs Medical Center, San Diego, California 92161, Departments of ${ }^{2}$ Psychiatry and ${ }^{3}$ Neurosciences, University \\ of California at San Diego, La Jolla, California 92093, and ${ }^{4}$ The Salk Institute, La Jolla, California 92037
}

Patient RB became amnesic following an episode of global ischemia that resulted in a bilateral lesion of the CA1 field of the hippocampus. This finding suggested that damage restricted to the hippocampus is sufficient to produce clinically significant memory impairment. To evaluate further the effect of ischemic brain damage on memory, we have developed an animal model of cerebral ischemia in the monkey. Monkeys were subjected to $15 \mathrm{~min}$ of reversible ischemia, using a noninvasive technique involving carotid occlusion and pharmacologically induced hypotension. These monkeys sustained significant loss of pyramidal cells in the CA1 and CA2 fields of the hippocampus, as well as loss of somatostatin-immunoreactive cells in the hilar region of the dentate gyrus. Cell loss occurred bilaterally throughout the rostrocaudal extent of the hippocampus but was greater in the caudal portion. Except for patchy loss of cerebellar Purkinje cells, significant damage was not detected in areas outside the hippocampus, including adjacent cortical regions, that is, entorhinal, perirhinal, and parahippocampal cortex, and other regions that have been implicated in memory function. On behavioral tests, the ischemic monkeys exhibited significant and enduring memory impairment. On the delayed nonmatching to sample task, the ischemic monkeys were as impaired as monkeys with lesions of the hippocampal formation and adjacent parahippocampal cortex (the $\mathrm{H}^{+}$lesion). On two other memory tasks, the ischemic monkeys were less impaired than monkeys with the $\mathrm{H}^{+}$lesion. In neuropathological evaluations, it has always been difficult to rule out the possibility that significant areas of neuronal dysfunction have gone undetected. The finding that ischemic lesions produced overall less memory impairment than $\mathrm{H}^{+}$ lesions indicates that the ischemic monkeys (and by extension, patient $\mathrm{RB}$ ) are unlikely to have widespread neuronal dysfunction affecting memory that was undetected by histological examination. These results provide additional ev-

\footnotetext{
Received Nov. 21, 1991; revised Jan. 30, 1992; accepted Feb. 3, 1992.

This work was supported by the Medical Research Service of the Department of Veterans Affairs, NIH Grants NS19063 and NS16980, the McKnight Foundation, the Office of Naval Research, NIH Postdoctoral Fellowship 1F32MH09989 to R.P.C., and NSF Graduate Research Fellowship RCD9054731 to N.L.R. We thank J. E. Fleischer, M. S. Scheller, and M. H. Lornow for assistance in preparing the ischemic animals, and Barbara Mason for assisting with the neurohistological preparation of the brains. A research protocol describing all aspects of the present study that related to the use of animals (care and maintenance, surgery, behavioral testing, and death) was approved by the Animal Research Committees of the V.A. Medical Center, San Diego, and the University of California, San Diego.

Correspondence should be addressed to Stuart Zola-Morgan, Department of Psychiatry, University of California at San Diego, La Jolla, CA 92093.

Copyright (C) 1992 Society for Neuroscience $0270-6474 / 92 / 122582-15 \$ 05.00 / 0$
}

idence that the hippocampus is a focal site of pathological change in cerebral ischemia, and that damage limited to the hippocampus is sufficient to impair memory.

Patient RB developed anterograde amnesia at the age of 52 following an episode of global ischemia (Zola-Morgan et al., 1986). During the 5 years that he survived, the only cognitive deficit that was detected was moderately severe memory impairment. Upon his death, histological examination revealed a circumscribed bilateral lesion involving the entire CAl field of the hippocampus. Minor pathology was observed elsewhere, for example, in the left globus pallidus and right postcentral gyrus, but the only damage that could be reasonably associated with the memory deficit was in the hippocampus. Recently, another case of memory impairment associated with bilateral damage limited to the hippocampus has been reported, in this instance following generalized seizures (Victor and Agamanolis, 1990).

Previous studies with rodents indicate that ischemia damages the hippocampus, particularly the CAl field, and produces memory impairment (for review, see Davis and Volpe, 1990). To investigate further the effect on memory of ischemic brain damage, and hippocampal damage in particular, we have developed an animal model of cerebral ischemia in the monkey. Surgical lesions in the monkey, which damage bilaterally the hippocampus and underlying parahippocampal and posterior entorhinal cortex (the $\mathrm{H}^{+}$lesion), produce moderately severe memory impairment (Mishkin, 1978; Mahut et al., 1982; ZolaMorgan and Squire, 1986; Zola-Morgan et al., 1989a). Relatively little information is available about the effects on memory of even smaller lesions restricted to the hippocampus itself. One approach to producing restricted hippocampal lesions is to combine stereotaxic neurosurgery with magnetic resonance (MR) imaging (Alvarez-Royo et al., 1991; Clower et al., 1991; Squire and Zola-Morgan, 1991). Another approach, described here, is to evaluate memory function in monkeys who have developed hippocampal pathology as the result of a period of cerebral ischemia.

Identifying the severity of memory impairment associated with ischemia should make it possible to address a fundamental issue pertaining to the neuropathological evaluation of ischemic brain tissue. Neuropathological assessment on its own can never exclude the possibility that significant neuronal damage has escaped detection. For example, neuronal dysfunction sufficient to impair memory might occur outside the hippocampus but not be detectable because abnormal neurons survive and do not progress to cell death. Indeed, one cannot rule out altogether the possibility that some ischemic damage beyond the CAl 
region might have occurred in patient $\mathrm{RB}$, which was not detected by histological analysis.

Monkeys with ischemic lesions can illuminate this issue because they can be tested on the same memory tests given previously to monkeys with surgical lesions of the medial temporal lobe. The findings from monkeys with surgical lesions provide specific predictions about the severity of memory impairment that should result from different amounts of tissue damage. For example, if ischemic monkeys have significant damage to memory-related areas outside the hippocampus itself, then they might exhibit memory impairment as severe as or even more severe than the impairment exhibited by monkeys with $\mathrm{H}^{+}$lesions. Alternatively, if ischemic monkeys have damage limited to the hippocampus, they might exhibit less impairment than that exhibited by monkeys with $\mathrm{H}^{+}$lesions. Thus, behavioral testing provides a method for corroborating the findings from histological analysis.

In the present study, we investigated the effects of cerebral ischemia in monkeys. The monkeys were evaluated on three memory tests sensitive to human ischemia and two memory tests analogous to ones that amnesic patients perform normally. These behavioral findings were compared to the behavioral findings from a group of normal monkeys and two groups of monkeys with surgical damage to the medial temporal lobe that have been studied previously. One of these groups had bilateral surgical lesions of the hippocampal formation and underlying cortex (the $\mathrm{H}^{+}$lesion; Zola-Morgan et al., 1989a). A second group had larger lesions that included the hippocampal formation, the amygdala, and underlying cortex (the $\mathrm{H}^{+} \mathrm{A}^{+}$lesion; Zola-Morgan and Squire, 1985). After the completion of behavioral testing, we carried out extensive, quantitative neurohistological analysis on the ischemic brains, focusing on the hippocampus, to determine whether CA1 damage is a consistent effect of cerebral ischemia in the monkey and to determine the extent of damage within the hippocampus. We also evaluated the extent of damage in a number of brain regions other than the hippocampus.

\section{Materials and Methods}

\section{Subjects}

Cynomolgus monkeys (Macaca fascicularis) were used, all weighing between 3.0 and $4.8 \mathrm{~kg}$ at the beginning of the study. Findings from 18 monkeys who underwent behavioral testing to evaluate memory will be presented. Additional monkeys were used to develop the protocol for producing ischemia $(n=6)$ or were used as control animals in postmortem analyses of neuropathology $(n=7)$. Based on weight-age tables (Hartley et al., 1984; Szabo and Cowan, 1984), the monkeys were estimated to be 3-5 years old. Monkeys were maintained on a daily ration of Purina Monkey Chow, supplemented weekly by fruits and vegetables.

Monkeys used to evaluate memory function (four groups, $n=18$ ). Four male monkeys sustained $15 \mathrm{~min}$ of cerebral ischemia (ISC group). Four other monkeys (two males, two females) received bilateral lesions of the medial temporal lobe that included the amygdala, the hippocampus, and the cortex adjacent to these structures, that is, perirhinal, entorhinal, and parahippocampal cortex $\left(\mathrm{H}^{+} \mathrm{A}^{+}\right.$group $)$. Behavioral data for this group have been presented as part of previous reports (ZolaMorgan et al., 1982, 1991; Zola-Morgan and Squire, 1984, 1985). In addition, three female monkeys received bilateral lesions limited to the hippocampal formation and the parahippocampal cortex $\left(\mathrm{H}^{+}\right.$group). Behavioral data for this group have also been presented previously (Zola-Morgan and Squire, 1986; Zola-Morgan et al., 1989a). Finally, seven male monkeys comprised an unoperated, normal control group (group N). Behavioral data for three of these monkeys (NI-N3) were reported previously (referred to as N4-N6 in Zola-Morgan et al., 1989c). Behavioral data for the remaining monkeys in group $\mathrm{N}$ appear here for the first time (referred to here as N4-N7). All monkeys were given the tests described below in the same sequence, using the same apparatus and test stimuli.
Monkeys used to develop the procedure for producing ischermia $(n=$ 6). Six male monkeys were used to identify the optimal duration of cerebral ischemia that would produce cell loss in the hippocampus with minimal behavioral dysfunction, as determined by daily neurologic assessments during the 2 weeks following ischemia. The duration of ischemia for the six monkeys ranged from 14 to $18 \mathrm{~min}: 14 \mathrm{~min}$, one monkey; $15 \mathrm{~min}$, two monkeys; $16 \mathrm{~min}$, one monkey; $17 \mathrm{~min}$, one monkey; $18 \mathrm{~min}$, one monkey. Monkeys given 14-16 min of ischemia achieved normal or nearly normal neurologic status within 2 weeks of the ischemic episode. The two monkeys that underwent 17 or $18 \mathrm{~min}$ of ischemia, however, exhibited considerable neurologic dysfunction (e.g., ataxia, motor weakness and incoordination, inability to track objects visually), and these two monkeys exhibited little improvement in neurologic status during the survival period. All six monkeys were killed 2 weeks after ischemia.

Monkeys used as control animals for histological analysis $(n=7)$. These monkeys had been used in separate anatomical studies involving anterograde and retrograde tracer injections (e.g., Pitkanen and Amaral, 1991). Brain tissue from these animals was processed for comparison with the histological findings from the two ischemic groups. The hippocampal formation was not involved in any of the injections and appeared completely normal in all seven animals.

\section{Ischemia procedure}

Preparation. The procedure was modified from earlier methods developed for monkeys (Nemoto et al., 1977; Steen et al., 1985; Fleischer et al., 1987). Monkeys were anesthetized in a specially designed Plexiglas box using $4 \%$ halothane and $66 \%$ nitrous oxide in $\mathrm{O}_{2}$ and then removed, intubated, and paralyzed with pancuronium $(0.15 \mathrm{mg} / \mathrm{kg}$, i.m.). Ventilation was controlled by a Harvard pump, and anesthesia was maintained with $0.5 \%$ halothane and $66 \%$ nitrous oxide. Additional doses of pancuronium $(0.02 \mathrm{mg} / \mathrm{kg}$, i.v.) were given as needed. A catheter was placed in the saphenous vein and, after a blood sample was obtained for glucose analysis, $50 \mathrm{ml}$ of $5 \%$ dextrose in $0.45 \%$ normal saline was infused during a period of 10-15 min. Following sterile preparation, femoral artery and vein catheters were inserted for monitoring of mean arterial pressure (MAP). Body temperature was maintained near $37^{\circ} \mathrm{C}$ using servo-controlled heat lamps and circulating water blankets. Platinum needle electroencephalographic (EEG) electrodes were attached to the monkey's head, and continuous EEG tracings were begun. MAP was stabilized in the range of $80-120 \mathrm{~mm} \mathrm{Hg}$, and monitored variables included arterial blood gases, blood glucose concentration, heart rate, electrolytes, and hematocrit.

Induction of ischemia. A pediatric blood pressure cuff was placed around the monkey's neck and strapped in place. The cuff served as a tourniquet during the period of ischemia. Halothane was discontinued and, after $3 \mathrm{~min}$, hypotension was induccd by infusing trimethaphan (20-40 mg, i.v., depending on the weight of the monkey and the initial MAP). An additional 10-20 mg of trimethaphan was given when MAP had decreased by $20-30 \mathrm{~mm} \mathrm{Hg}$. When MAP decreased to $60 \mathrm{~mm} \mathrm{Hg}$, the neck cuff was abruptly inflated to a pressure of $1500 \mathrm{~mm} \mathrm{Hg}$, a stopwatch was started to record the duration of ischemia, and ventilation with $100 \% \mathrm{O}_{2}$ was begun. During the ischemic episode, MAP was maintained at approximately $50 \mathrm{~mm} \mathrm{Hg}$ by the use of additional trimethaphan boluses.

Continuous EEG recordings provided a measure of the onset and duration of isoelectric EEG. For the four ISC animals, the EEG became isoelectric at an average of $16 \mathrm{sec}$ following cuff inflation, and continuous EEG activity returned an average of $76 \mathrm{~min}$ after the ischemic episode.

Postischemic period. At the end of the ischemic period, the neck tourniquet was deflated and removed. MAP was elevated and maintained at $80-120 \mathrm{~mm} \mathrm{Hg}$ by the use of norepinephrine and trimethaphan. Ventilation with $100 \% \mathrm{O}_{2}$ was continued for $2 \mathrm{hr}$ postischemia, followed by $50 \% \mathrm{O}_{2}, 50 \% \mathrm{~N}_{2} \mathrm{O}$ until extubation. During this time, monkeys were kept immobilized with additional doses of pancuronium (0.2$0.5 \mathrm{mg}, \mathrm{i} . \mathrm{v}$.). When continuous EEG had returned for a period of at least $1 \mathrm{hr}$, the effects of pancuronium were reversed with neostigmine $(0.07 \mathrm{mg} / \mathrm{kg}$, i.v.) and glycopyrolate $(0.012 \mathrm{mg} / \mathrm{kg}, \mathrm{i} . \mathrm{v}$.$) . Following ex-$ tubation, monkeys were moved to a postoperative recovery area where they were maintained in a specially designed incubator. Monkeys were typically returned to their home cages within 1 week. Neurologic status was assessed daily for 2 weeks after the ischemic procedure by evaluating level of consciousness (normal, clouded, coma), respiration (normal, abnormal, respirator dependent), oculomotor function (pupil size, light 


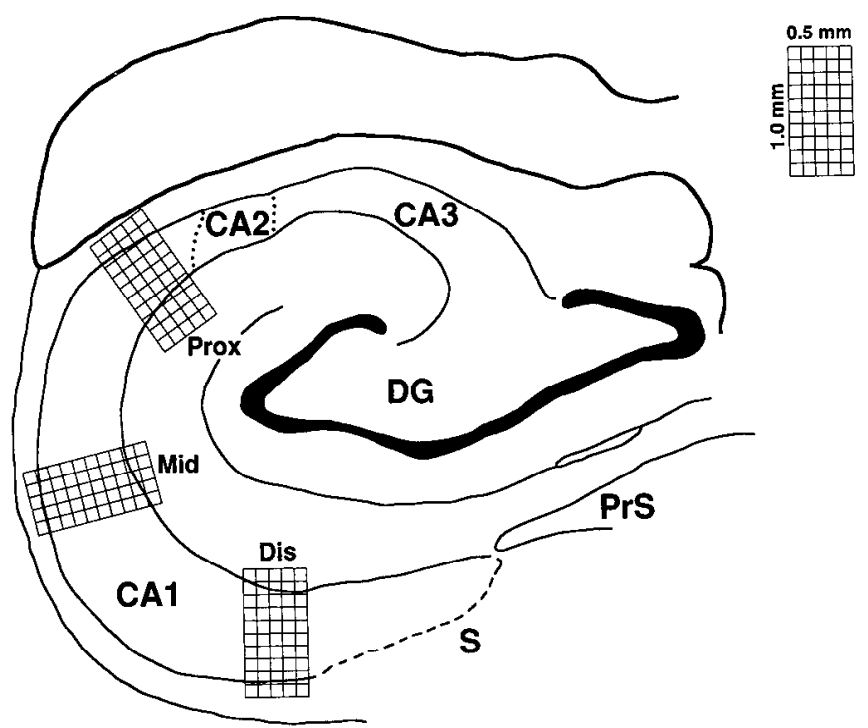

Figure 1. A schematic drawing of a coronal section of the hippocampus in a normal monkey. The pyramidal cell fields have been outlined. A grid $(1.0 \mathrm{~mm} \times 0.5 \mathrm{~mm})$ was placed over three separate regions of the transverse axis of the CA1 field of the hippocampus labeled here as proximal (Prox), midtransverse (Mid), and distal (Dis), and all pyramidal cells were counted that lay within the borders of the grid. Dotted lines indicate boundaries between CA1, CA2, and CA 3 fields. Dashed line indicates boundary between $C A 1$ field and subiculum. $D G$, dentate gyrus; $S$, subiculum; $\operatorname{PrS}$, presubiculum.

reflex, visual tracking, eye position), motor and sensory function (grasp, body position, paralysis), and behavior (walking, feeding, sitting).

\section{Surgical groups}

$\mathrm{H}^{+}$group. The surgical procedure used for making hippocampal formation lesions $\left(\mathrm{H}^{+}\right)$has been described in detail previously (Zola-Morgan and Squire, 1986). The hippocampus, dentate gyrus, and subicular complex were removed. The removal also included much of the parahippocampal gyrus and approximately the posterior half of the entorhinal cortex.

$H^{+} A^{+}$group. The surgical preparation for the $\mathrm{H}^{+} \mathrm{A}^{+}$group has been described in detail previously (Zola-Morgan and Squire, 1984, 1985). The lesion included the amygdala, the hippocampus, dentate gyrus, and subicular complex, as well as perirhinal cortex, entorhinal cortex, and parahippocampal cortex (areas TF and TH of Bonin and Baily, 1947).

\section{Behavioral testing}

All groups were allowed 6-8 weeks of recovery prior to the start of behavioral testing. Testing was carried out in a Wisconsin General Test Apparatus (Harlow and Bromer, 1938). During four to six daily sessions of pretraining, monkeys learned to obtain food by displacing objects that covered any of three food wells located on a stimulus tray in front of the testing chamber. Five different tasks (described in detail in ZolaMorgan and Squire, 1984, 1985; Zola-Morgan et al., 1989b) were then administered to all monkeys in the order listed under behavioral findings in the Results. Three of the tasks (trial-unique nonmatching to sample, delayed retention of object discriminations, and eight-pair concurrent discrimination learning) are known to be sensitive to human amnesia, and two of the tasks (pattern discrimination and the Lifesaver motor skill task) are analogous to tasks that human amnesic patients can perform normally.

\section{Histological processing}

Ischemic groups and the anatomical control group. At the end of the 2 week survival period, in the case of the animals used to develop the ischemia procedure $(n=6)$, or at the complction of bchavioral testing, in the case of the ISC group $(n=4)$, monkeys were deeply anesthetized with Nembutal and their heads packed in ice prior to transcardial perfusion. The same perfusion procedure was used for all the monkeys that had sustained ischemia and for three of the seven monkeys in the an- atomical control group. The monkeys were perfused for $2 \mathrm{~min}$ at a rate of $250 \mathrm{ml} / \mathrm{min}$ with $1 \%$ paraformaldehyde $\left(4^{\circ} \mathrm{C}\right)$, followed by $10 \mathrm{~min}$ at $250 \mathrm{ml} / \mathrm{min}$ with $4 \%$ paraformaldehyde and then with the same solution at a rate of $100 \mathrm{ml} / \mathrm{min}$ for $50 \mathrm{~min}$. This was followed by a 20 min rinse with cold $5 \%$ sucrose at $100 \mathrm{ml} / \mathrm{min}$. The other four anatomical control animals were perfused using a $\mathrm{pH}$-shift fixative protocol: $0.9 \%$ $\mathrm{NaCl}, 4^{\circ} \mathrm{C}$ for $2 \mathrm{~min} ; 4 \%$ paraformaldehyde in $0.1 \mathrm{~m}$ sodium acetate buffer, $\mathrm{pH} 6.5,4^{\circ} \mathrm{C}$ for $20 \mathrm{~min} ; 4 \%$ paraformaldehyde in $0.1 \mathrm{~m}$ sodium borate buffer, $\mathrm{pH} 9.5,4^{\circ} \mathrm{C}$ for $30 \mathrm{~min}$. All brains were then blocked in situ in the coronal plane, removed from the skull, and cryoprotected in a solution of $10 \%$ glycerol with $2 \%$ dimethyl sulfoxide (DMSO) in a 0.1 M phosphate buffer for $1 \mathrm{~d}$, followed by $20 \%$ glycerol with $2 \%$ DMSO for $2 \mathrm{~d}$. Blocks of tissue were rinsed in $10^{\circ} \mathrm{C}$ isopentane for $10-15 \mathrm{sec}$ and then rapidly frozen in $-70^{\circ} \mathrm{C}$ isopentane for $20 \mathrm{~min}$.

The blocks were either cut immediately or stored in a $-70^{\circ} \mathrm{C}$ freezer and cut at a later time. Tissue blocks were sectioned coronally at $50 \mu \mathrm{m}$ (for the group used to develop the ischemia procedure) or at $30 \mu \mathrm{m}$ (the ISC group and the anatomical con(rol groups) on a freezing microtome. One series (every eighth section) was collected in formalin for subsequent Nissl staining with thionin. An additional series of sections was collected in cold cryoprotectant solution for staining with antibodies directed against somatostatin-28 (S309; Benoit et al., 1982) and glial fibrillary acidic protein (GFAP). Finally, for monkeys used to develop the ischemic procedure, an additional series of sections was collected for staining with a modified silver impregnation technique (Nadler and Evenson, 1983) to reveal degenerating neuronal elements (Gallyas, 1979).

Analysis of ischemic cell loss within hippocampus. Examination of sections from the six monkeys used to develop the ischemic procedure indicated that the CAl field of the hippocampus sustained the greatest cell loss. A quantitative analysis of the number of CA1 pyramidal cells was therefore carried out in the four ISC monkeys and four anatomical control monkeys. Using a combination of bright-field microscopy and an eyepiece etched with a rectangular micrometer grid $(1.0 \mathrm{~mm} \times 0.5$ $\mathrm{mm}$ ), cells were counted in Nissl-stained coronal sections in three separate regions of the hippocampus: immediately adjacent to the CA2 border (proximal CA1), midway through the transverse extent of CAl (midtransverse CA1), and near the border with the subiculum (distal CA1) (Fig. 1). Separate counts were obtained for the left and right hippocampus. Cell counts were carried out on every fourth Nissl-stained section through the rostrocaudal extent of the hippocampus (i.e., at 960 $\mu \mathrm{m}$ intervals). For descriptive purposes, the rostrocaudal extent of the hippocampus was divided into quadrants, and data are presented separately for each quadrant.

For each section in which cells were counted, the cross-sectional area of the CAl pyramidal cell field was also determined. First, camera lucida drawings of the perimeter of the CAl field were made directly from each slide at a magnification of $30 \times$. These drawings were then traced using a digitizing tablet linked to a microcomputer to compute an areal measurement for each section. The rostrocaudal extent of the hippocampus was divided into quadrants as in the cell loss analysis, and the $\mathrm{CAl}$ area measurements obtained from the ISC monkeys were compared to CA1 area measurements from the four anatomical control monkeys. For each animal, the total volume of the CAl pyramidal cell field was estimated by multiplying the sum of the areal measurements by the section interval $(960 \mu \mathrm{m})$.

Loss of somatostatin (SS)-immunoreactive cells in the hilar region of the dentate gyrus has bcen reported following ischemia in rodents (Johansen et al., 1987). To determine whether a similar loss occurred in primates subjected to ischemia, SS-stained sections from three monkeys in the ISC group (ISC1, ISC2, and ISC3) and three anatomic control monkeys were examined. (Animal ISC4 was not included in this analysis due to the poor quality of the immunostained tissue.) SS-positive cells were counted in the hilar region of the dentate gyrus at $480 \mu \mathrm{m}$ intervals along the rostrocaudal extent of the hippocampus. The hilar region was divided into the same four rostrocaudal quadrants used in the cell count analysis of the CA1 field. To determine if the loss of SS-positive cells was specific to the dentate gyrus, SS-positive cells were also counted at four separate levels of the entorhinal cortex, an area where numerous SS-positive cells are also observed (Bakst et al., 1985).

Analysis of ischemic cell loss outside the hippocampus. The brains from both the ISC group and the group used to develop the ischemic procedure were also examined to identify brain regions outside the hippocampus that might also have been damaged. Thionin-stained sections and bright-field microscopy were used to examine other brain areas, including those that have been suggested to be involved in mem- 

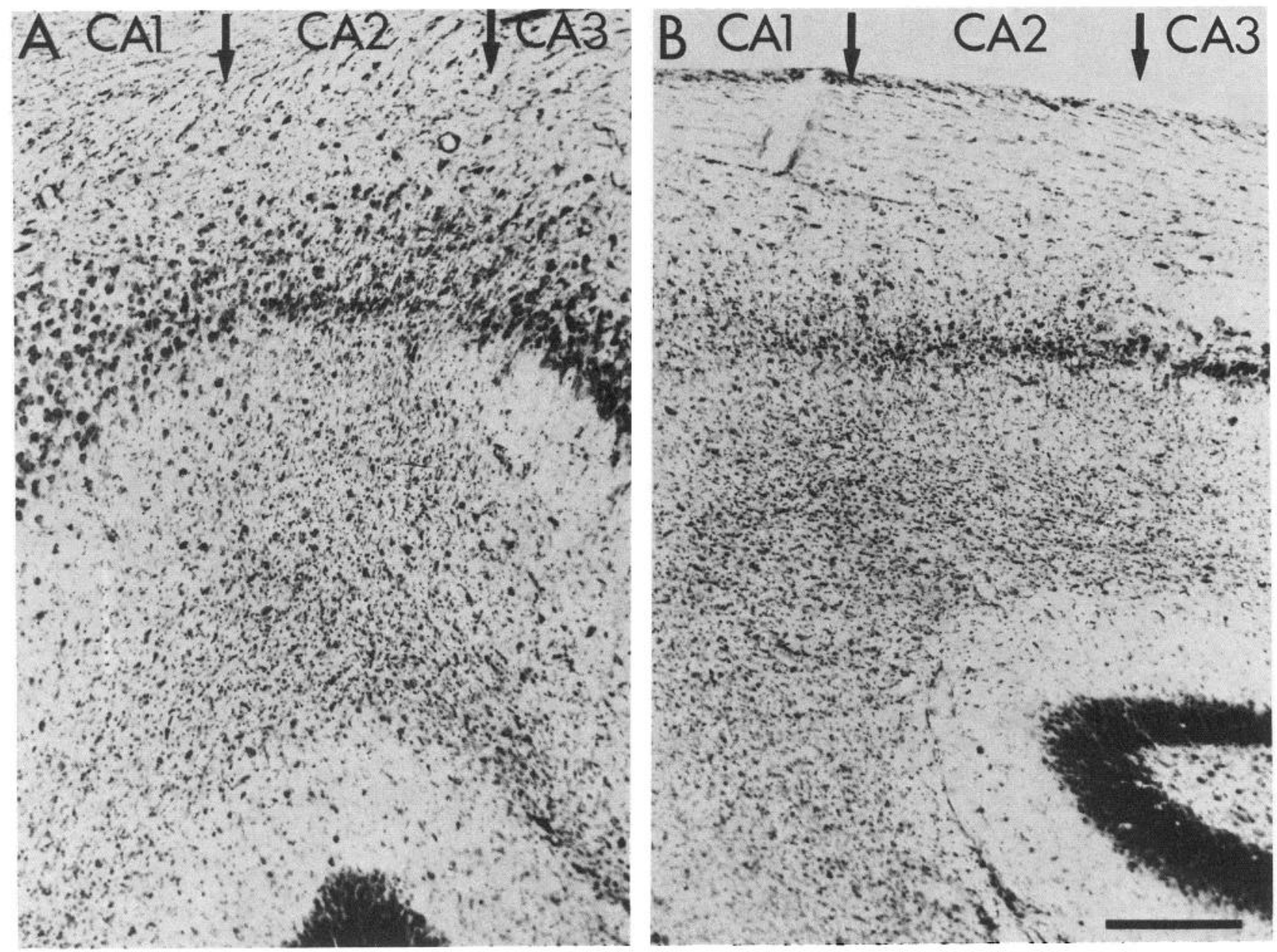

Figure 2. Representative thionin-stained coronal sections from one of the monkeys used to develop the ischemia procedure. The sections show pyramidal cell loss from the rostral $(A)$ and caudal $(B)$ hippocampus (arrows indicate boundaries between CA1, CA2, and CA3 fields). This monkey underwent $15 \mathrm{~min}$ of ischemia and sustained moderate pyramidal cell loss. As in the other animals in this group, cell losses were greater caudally than rostrally. The heavy glial scarring in CA1 and extending into CA2 in the animals in this group is presumably a short-term effect of ischemia related to the death of pyramidal cells. The gliosis extends deep into the strata radiatum and moleculare, where degeneration of CA1 pyramidal cell dendrites has taken place. Scale bars, $250 \mu \mathrm{m}$.

ory, that is, the perirhinal and parahippocampal cortices, the amygdala, the mammillary nuclei, and the mediodorsal nucleus of the thalamus. In addition, sections stained with the modified silver impregnation technique were examined using both bright-field and dark-field microscopy.

To investigate further the possibility that damage to regions outside the hippocampus might have occurred, cells were counted in cortical area TF, a polymodal association cortex of the parahippocampal gyrus that has been linked to memory function (Zola-Morgan et al., 1989c; Amaral et al., 1990; Squire and Zola-Morgan, 1991). Using bright-field microscopy and the micrometer grid as described for the CAl pyramidal cell counts, a single thionin-stained coronal section was sampled at the midpoint of the rostrocaudal length of TF. The grid was positioned over area TF at the center of its mediolateral axis, with the long axis of the grid oriented perpendicular to the pial surface. The grid encompassed all of the layers of area TF.

\section{Results}

\section{Histological findings}

Damage within the hippocampus following ischemia: group used to develop the ischemia procedure. In the six animals in this group, thionin-stained brain sections revealed cell loss that ranged from moderate (in monkeys who sustained 14-17 $\mathrm{min}$ of ischemia) to severe (in the monkey who sustained $18 \mathrm{~min}$ of isch- emia). In all animals, cell loss was greater caudally than rostrally (Fig. 2). CA1 cell loss in the monkey who sustained $18 \mathrm{~min}$ of ischemia was substantially greater than in any other animal in this group. However, there was no systematic relationship between CA1 damage and the duration of ischemia for the five animals that sustained ischemia lasting from 14 to $17 \mathrm{~min}$. Brain sections stained with the modified silver impregnation technique revealed degenerating neuronal elements in the CA1 and CA2 fields of the hippocampus. Consistent with the pattern of cell loss, the degeneration was more prominent caudally than rostrally (Fig. 3). As a result of these pilot studies, we determined that 15 min was the optimal duration of ischemia for the preparation of the animals to be used for behavioral analysis (ISC group).

Damage within the hippocampus following ischemia: ISC group. Pyramidal cell loss and glial scarring were evident in all four ISC monkeys. Monkey ISC2 sustained much greater cell loss overall than the other three ISC monkeys, and the findings from this monkey are not included in the statistical analyses that follow. In all four monkeys, cell loss was most prominent in the CA1 field of the hippocampus (Fig. 4). Cell loss also 

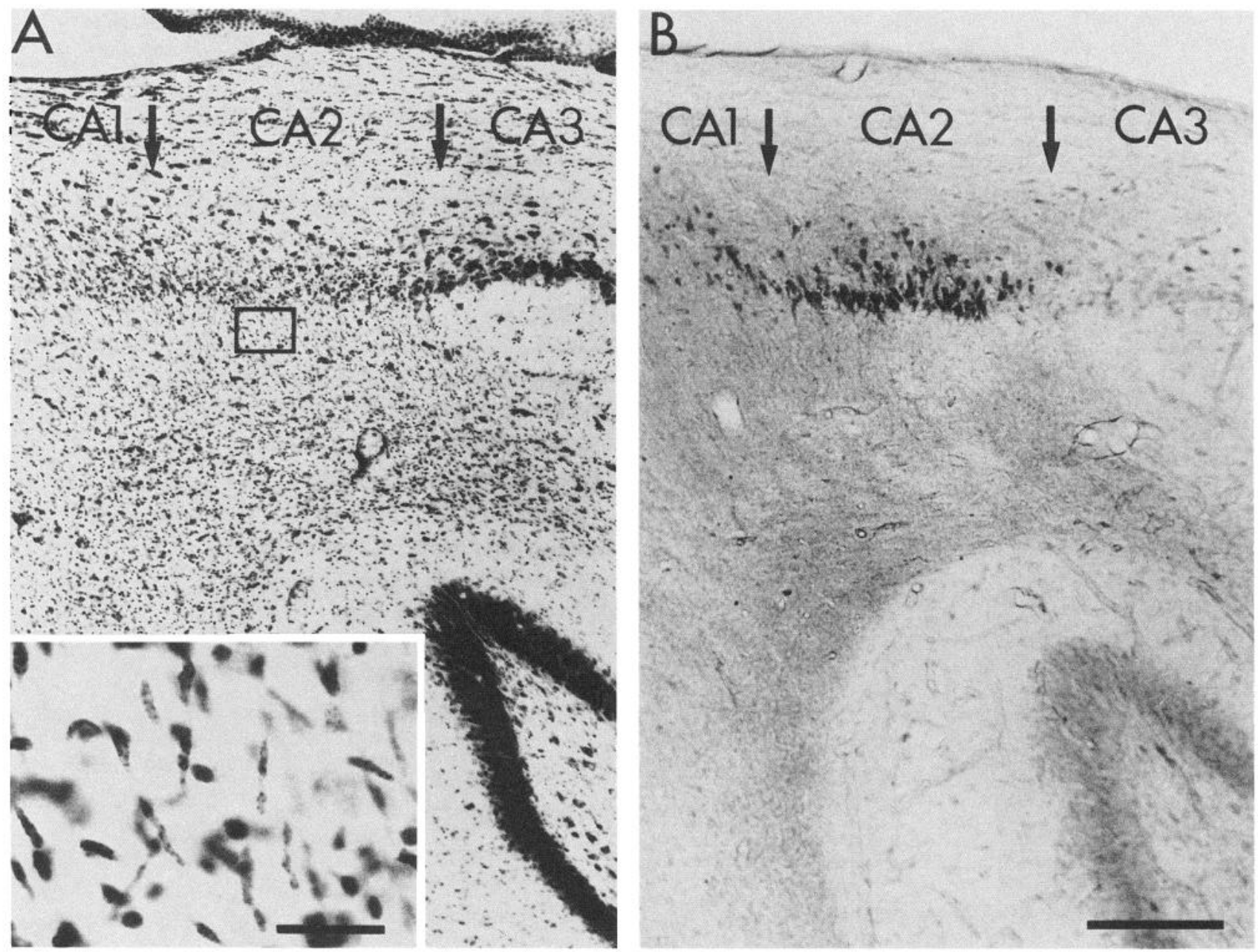

Figure 3. A thionin-stained coronal section $(A)$, through the mid-hippocampus of the animal in Figure 2 is shown together with an adjacent section $(B)$ stained with the modified silver impregnation technique. Arrows indicate boundaries between CA1, CA2, and CA3 fields. The pattern of degeneration seen in $B$ coincides with the pattern of cell loss observed in $A$. In $B$, a dense network of dark-staining, degenerating fibers is evident both within and deep to the pyramidal cell layer. Substantial degenerating neuronal profiles in $B$ appear within the CA2 field of the hippocampus, demonstrating that pyramidal cell loss even in animals with moderate levels of overall damage was not limited to the CA1 field. Inset, A $7.8 \times$ enlargement of a region near the border of the CA1 and CA2 fields (small rectangle in $A$ ), showing small, fusiform cells that were frequently observed in regions of the hippocampus following ischemia. Scale bars: $A$ and $B, 250 \mu \mathrm{m}$; inset, $25 \mu \mathrm{m}$.

occurred in the CA2 field, particularly at the border with the CA1 field. In some cases and at some rostrocaudal levels, cell loss extended for a short distance into the CA3 field (Fig. 5).

Tissue stained with antibodies for GFAP also provided evidence of glial proliferation in fields CA1 and CA2 in all four animals. Specifically, a marked proliferation of astrocytes was observed both within and deep to the pyramidal cell layer. This proliferation of astrocytes appeared more substantial in the caudal portion of the hippocampus than in the rostral portion, an observation consistent with the findings of cell loss.

Pyramidal cell loss was evident across the transverse axis of the hippocampus in proximal, midtransverse, and distal portions of the CA1 field (Fig. 6). A three-way ANOVA (2 groups, 3 portions of the CA1 field, and 4 quadrants) revealed significant effects of group $(F[1,6]=14.73, p<0.01)$, portion $(F[2,77]=$ $12.84, p<0.01)$, and quadrant $(F[3,77]=8.08, p<0.01)$, a significant group $\times$ quadrant interaction $(F[3,77]=7.17, p<$ $0.01)$, and no other interactions $(F \mathrm{~s}<1.0)$. Separate comparisons between the normal group and the ISC group (ISC1, ISC3, ISC4) averaged across the three portions of the CA1 field (prox- imal, midtransverse, and distal) revealed that the ISC monkeys sustained significant cell loss in each of the four quadrants [cell loss in quadrant $1,11 \%(t=5.59, p<0.01)$; quadrant $2,12 \%$ $(t=3.20, p<0.05)$; quadrant $3,14 \%(t=2.94, p<0.05)$; quadrant $4,38 \%(t=3.29, p<0.05)]$. Cell loss in the most caudal quadrant $(38 \%)$ was about three times greater than cell loss in each of the rostral three quadrants (mean percentage cell loss, 12\%). In monkey ISC2, who exhibited much more cell loss than the other three ISC animals, this same rostrocaudal pattern of cell loss was observed (quadrants $1-4,55 \%, 83 \%, 98 \%, 99 \%$, respectively).

Areal measures of the CA1 field revealed reductions in the size of the CA1 field in all four ISC monkeys that were consistent with the pattern of cell loss just described. Specifically, the overall area of the CA1 field was decreased by approximately $18 \%$ in monkeys ISC1, ISC3, and ISC4; the decrease in area amounted to $34 \%$ in the caudalmost quadrant (Fig. 7). In monkey ISC2, who lost nearly all CA1 pyramidal cells in the caudal half of the hippocampus, the overall reduction in CA1 area was $74 \%$ ( $95 \%$ in the caudalmost quadrant). The areal measures were also 

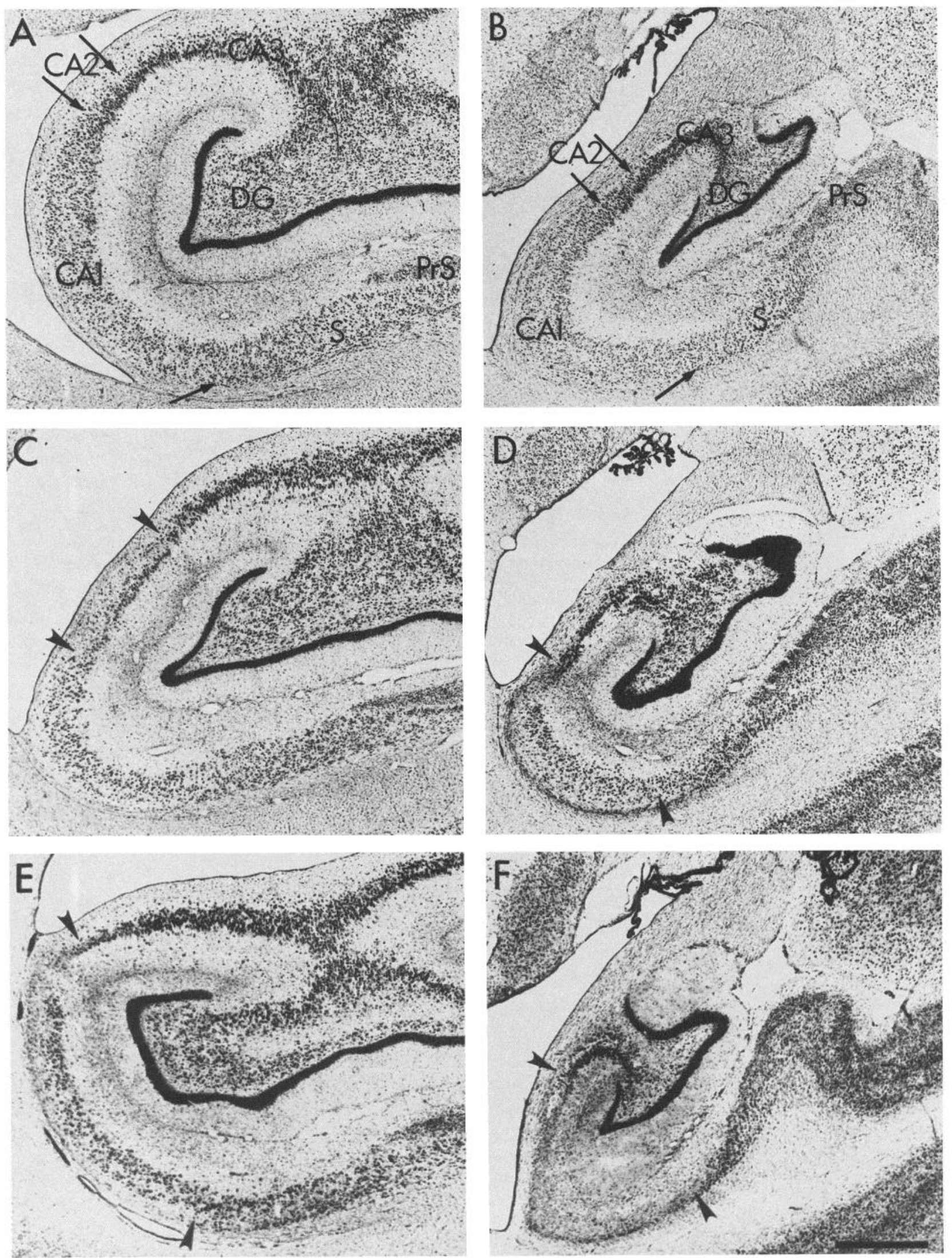

Figure 4. Thionin-stained coronal sections through the rostral (left column) and caudal (right column) hippocampus of a normal animal (A and $B)$ and of animals ISC3 $(C$ and $D)$ and ISC2 $(E$ and $F)$, who sustained moderate and severe CA1 pyramidal cell loss, respectively, following ischemia. In the normal animal $(A$ and $B)$, the arrows indicate boundaries between subiculum, CA1, CA2, and CA3 fields. For the ischemic animals, the region of heaviest cell loss is demarcated by arrowheads. Cell loss in the ischemic animals was greater in the caudal hippocampus $(D$ and $F)$ than in the rostral hippocampus $(C$ and $E)$. Abbreviations are as in Figure 1. Scale bar, $1 \mathrm{~mm}$. 

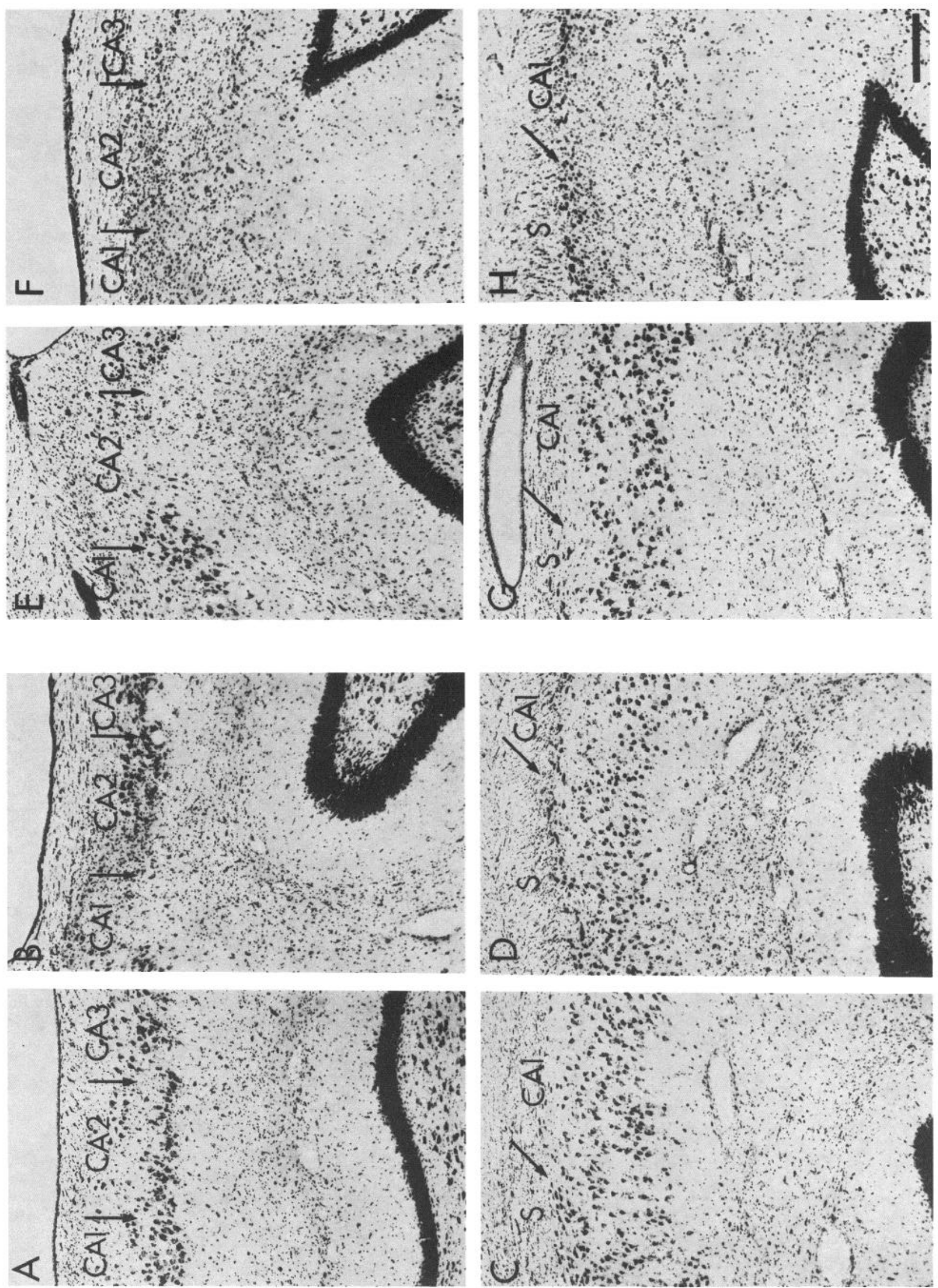

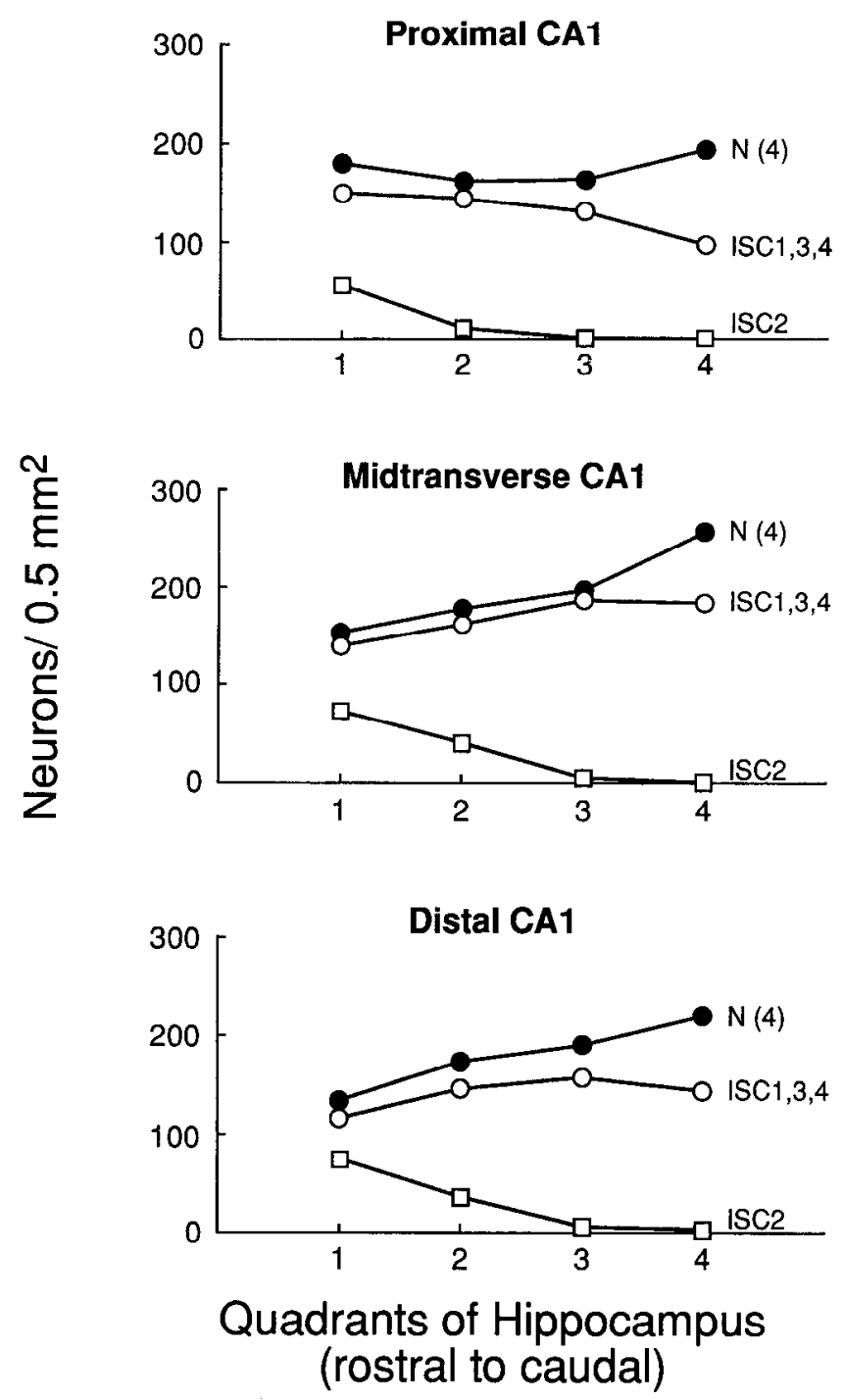

Figure 6. Pyramidal cells in the CA1 field in the four ISC monkeys and in four monkeys in the neuroanatomic control group $(N)$. Cells were counted in $0.5 \mathrm{~mm}^{2}$ regions in proximal (top), midtransverse (middle), and distal (bottom) hippocampus. The rostrocaudal extent of the hippocampus was divided into quadrants. One of the four ISC monkeys (ISC2) sustained much greater cell loss than the other three ISC monkeys (ISC1, ISC3, ISC4) and is shown separately. In all four ISC monkeys, pyramidal cell loss was greater in caudal than rostral hippocampus.

used to estimate the volume of the CAl field. The total volume of the CA1 pyramidal cell field was reduced by an average of $24 \%$ in monkeys ISC 1 , ISC 3 , and ISC 4 , and by $73 \%$ in monkey ISC2.

The three ISC monkeys who were examined for SS-containing

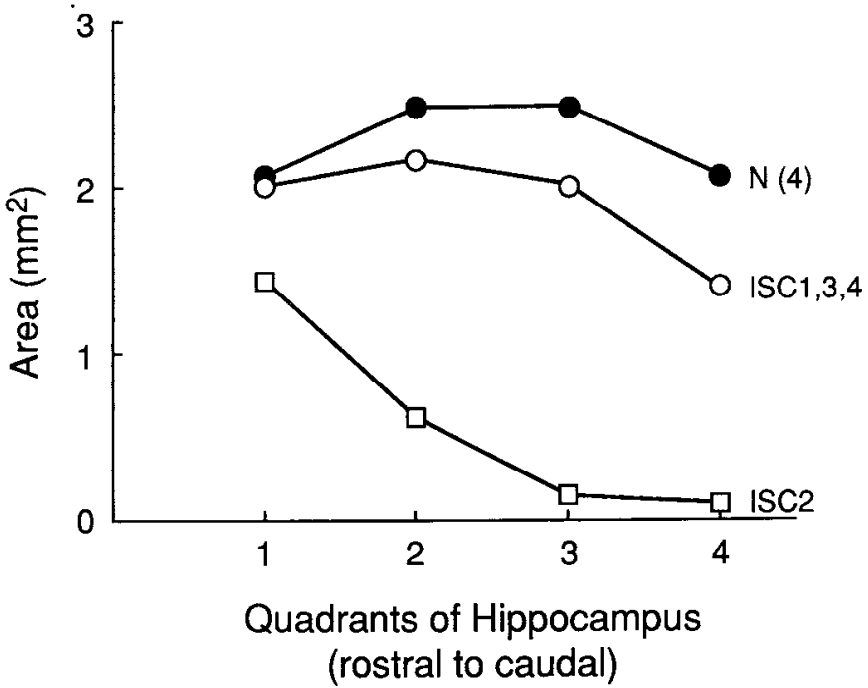

Figure 7. The area of the CA1 pyramidal cell field was measured in the same thionin-stained coronal sections in which cells were counted. Three ISC monkeys (ISC1, ISC3, and ISC4) exhibited only a small decrease in the area of CA1 in the rostral three-fourths of the hippocampus and a decrease of approximately $33 \%$ in the CAl area in the caudalmost quadrant. The area of the CA1 pyramidal cell field in animal $I S C 2$, shown separately, was much smaller overall than in the other ISC monkeys, a finding consistent with this animal's dramatic cell loss.

cells (ISC1, ISC2, and ISC3) tended to have fewer SS-immunopositive cells in the hilar region of the dentate gyrus than the anatomic control monkeys (Fig. 8). A two-way ANOVA revealed a marginal group effect and a quadrant effect $(F[1,5]=$ $7.2, p<0.06 ; F[3,18]=82.0, p<0.001$, respectively), and no interaction $(F<1.0)$. Both ISC and anatomic control monkeys had fewer SS-positive cells in the caudal quadrants of the hilar rcgion than in rostral quadrants (Figs. 8, 9). The decrease in SS staining did not appear to be related to the extent of CAl pyramidal cell loss. For example, the monkey with the most dramatic pyramidal cell loss (ISC2) had more SS-positive cells in the hilus than the other two ISC animals.

Damage outside the hippocampus following ischemia. The analysis of damage outside the hippocampus in the ISC monkeys was guided by an initial survey of material prepared from the six monkeys used to develop the ischemia protocol. These animals survived for only 2 weeks after the ischemic procedure. Accordingly, the brains of these animals could be processed using a modified silver staining procedure that reveals degenerating neuronal elements. This procedure provides a sensitive method for identifying areas of the brain affected by ischemia. First, the brain of the monkey that was given the longest period of ischemia (18 min) was examined. In this monkey, thioninstained sections revealed cell loss in the CA1 and CA2 fields of the hippocampus and accompanying glial proliferation that was

Figure 5. Representative thionin-stained coronal sections from animals ISC3 $(A-D)$ and ISC2 $(E-H)$, showing pyramidal cell loss from the CA fields of the hippocampus. Pyramidal cell loss was observed in both proximal hippocampus $(A$ and $B, E$ and $F)$ and distal hippocampus $(C$ and $D, G$ and $I)$. Animal ISC3, who sustained moderate cell loss following ischemia, had heavier losses caudally $(B$ and $D)$ than rostrally $(A$ and $C$ ). This pattern of pyramidal cell loss was observed in all ischemic animals. In animal ISC2, who had severe pyramidal cell loss following ischemia, some neurons are still present in CAl at rostral levels of the hippocampus ( $E$ and $G$ ), but caudally $(F$ and $H)$ no cells could be detected. Note also in $E$ and $F$ that cell loss extends well into fields CA2 and CA3. In all animals, it was clear that neurons were lost from fields CA2 and CA3, although this cell loss did not appear as substantial as the loss in field CA1. Arrows indicate boundaries between subiculum $(S), \mathrm{CA} 1, \mathrm{CA} 2$, and CA3 fields. Scale bar, $250 \mu \mathrm{m}$. 


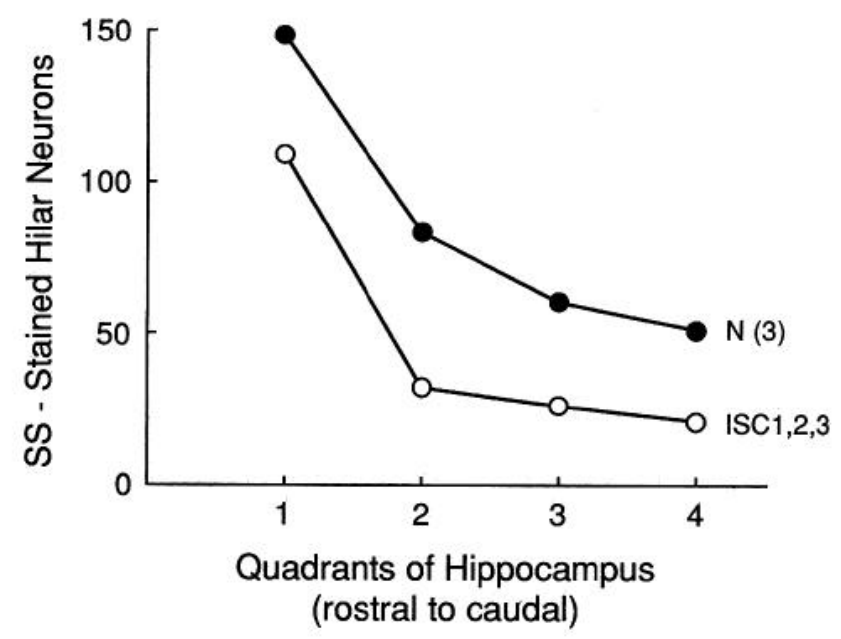

Figure 8. SS-immunopositive cells were counted in the hilar region of the dentate gyrus in three animals in the ISC group (ISC1, ISC2, and ISC3) and in three anatomic control animals $(N)$. The rostrocaudal extent of the hippocampus was divided into quadrants matching the divisions used in the assessment of CAl pyramidal cell loss (Fig. 4). The ISC animals had fewer SS-stained neurons in each of the four quadrants.

comparable to the cell loss in monkey ISC2, who suffered the most cell loss in the ISC group. A slight sparseness of neurons and mild gliosis were observed in the hilus of the dentate gyrus and in the subiculum. Brain sections stained by the modified silver impregnation technique revealed extensive degeneration in both the CA1 and CA 2 fields of the hippocampus, with some degeneration also apparent in the hilus of the dentate gyrus and in the subiculum. Terminal degeneration in the subiculum was also apparent, and the distribution was consistent with the known regions of termination of CAl fibers within the subiculum.

In addition to damage within the hippocampal formation, this animal exhibited degeneration and glial proliferation in several extrahippocampal areas. The most substantial degeneration was seen in the ventrolateral putamen, which showed marked neuronal loss and glial proliferation. Patchy loss of Purkinje cells was also observed in the cerebellum. The mammillary nuclei, as well as the mediodorsal and ventrothalamic nuclei, also exhibited very slight degeneration. Some degeneration and glial proliferation were also observed in the brainstem (e.g., in the oculomotor nuclei, the superior olive, and the vestibular nuclei). No evidence of degeneration was found in the amygdala or in several cortical regions that were examined, including the perirhinal cortex, parahippocampal cortex, and frontal cortex.

Examination of both thionin-stained tissue and tissue prepared using the modified silver impregnation technique from the brains of the five other monkeys in this group revealed degeneration and glial proliferation in many of these same areas. In no case, however, was damage in these areas greater than in the $18 \mathrm{~min}$ animal. Moreover, no brain areas were found to be damaged in these five animals that were intact in the $18 \mathrm{~min}$ animal.

Guided by the findings from the monkeys in this group, we examined carefully in the ISC group all of the areas that were damaged in the $18 \mathrm{~min}$ animal. Little or no evidence of pa-
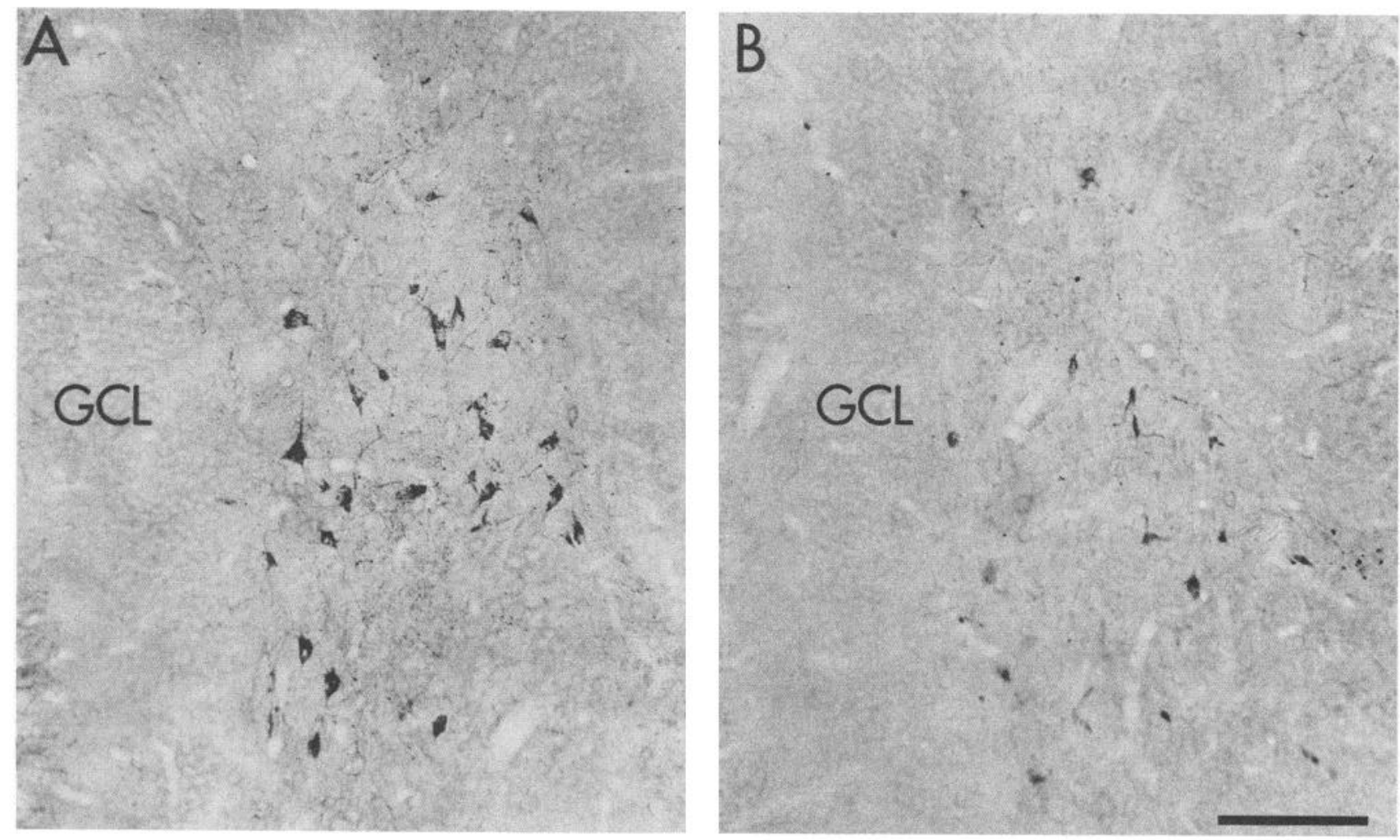

Figure 9. Coronal sections through the hilus of a neuroanatomic control monkey $(A)$ and monkey ISC3 $(B)$ stained for SS. Many fewer positive neuronal profiles were observed in the ISC animal. This same observation was made in all three of the ISC animals for which immunohistochemistry was possible. Monkey ISC3, the case shown in $B$, had a level of neuron loss that was intermediate for the three ISC animals stained for SS. $G C L$, granule cell layer of the dentate gyrus. Scale bar, $250 \mu \mathrm{m}$. 


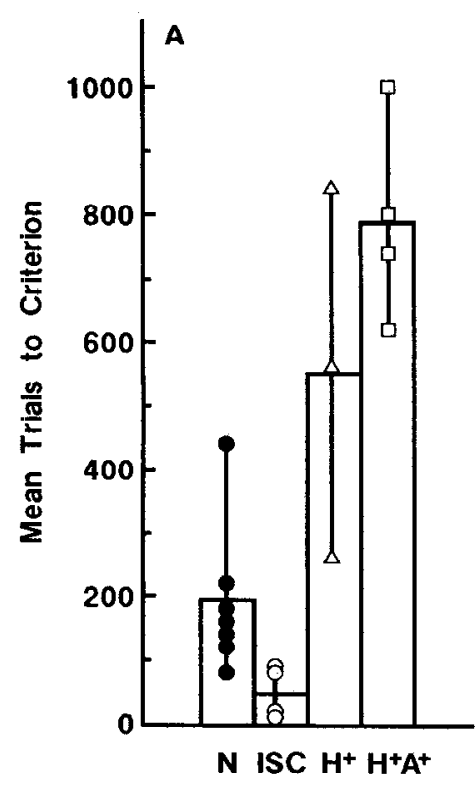

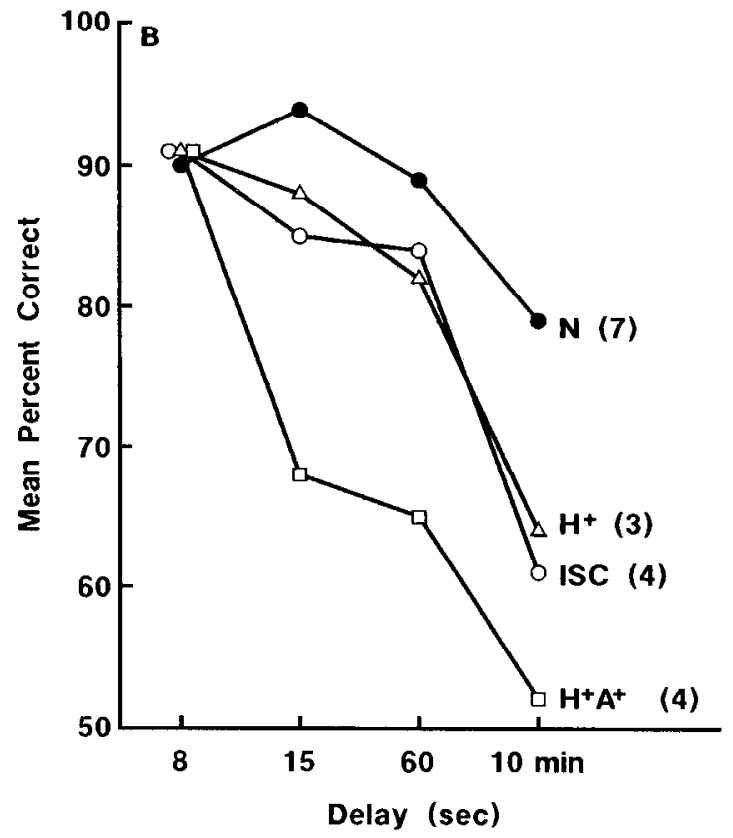

Figure 10. Performance on the delayed nonmatching to sample task by normal monkeys $(N)$, monkeys that underwent $15 \mathrm{~min}$ of cerebral ischemia (ISC), monkeys with lesions of the hippocampal formation $\left(\mathrm{H}^{+}\right)$, and monkcys with conjoint lesions of the hippocampus and amygdala that also damaged the adjacent cortical regions $\left(H^{+} A^{+}\right.$; Zola-Morgan and Squire, 1985). $A$, Initial learning of the task with a delay of 8 sec. Symbols show trials to criterion for individual animals (see Table 1). B. Performance across delays for the same groups. thology was found outside the hippocampus. In particular, the amygdala, perirhinal cortex, parahippocampal cortex, and frontal cortex all appeared normal. There was a slightly patchy appearance in the mammillary nuclei and the mediodorsal nucleus of the thalamus, indicating possible minor cell loss. In three of the ISC monkeys, some cells in the ventral putamen appeared slightly smaller and darker than normal. However, such pathology was barely detectable, and it was not observed in the remaining ISC monkey. The only other region in which cell loss was detected was the cerebellar cortex, where there was patchy loss of Purkinje cells.

Cell counts in cortical area TF were carried out in the four anatomical control monkeys and in three of the ISC monkeys (the thionin-stained tissue in this region for monkey ISC4 was not of sufficient quality to include in this analysis). There was no detectable cell loss in cortical area TF in any of the ISC monkcys. An avcrage of 1782 cells were counted within the borders of the counting grid in the four anatomical control monkeys, and an average of 1823 cells were counted in the three ISC monkeys $(t[5]<1.0)$.

$\mathrm{H}^{+}$group. The lesions in these animals were described previously (Zola-Morgan et al., 1989a). Monkeys $\mathrm{H}^{+} 1$ and $\mathrm{H}^{+} 2$ sustained complete bilateral hippocampal removals. The rostral third of the entorhinal cortex was intact in both cases, but layer II was eliminated due to retrograde degeneration. The posterior portion of the entorhinal cortex was directly damaged, and the lesion extended posteriorly and laterally to encompass the parahippocampal gyrus bilaterally. Monkey $\mathrm{H}^{+} 3$ had a smaller lesion involving about half of the hippocampal formation bilaterally. Approximately the anterior $30 \%$ of the hippocampal formation and the posterior $20 \%$ were not damaged by the ablation. The entorhinal cortex was intact, but there was partial loss of layer II cclls. There was also bilateral damage of the parahippocampal gyrus, but this was not as extensive as in the other two monkeys. At caudal levels, the ablation exceeded the dorsal limit of the ventricle and damaged the tail of the caudate nucleus, the lateral geniculate, and the optic radiations bilaterally. The amygdaloid complex was intact in $\mathrm{H}^{+} 1$ and $\mathrm{H}^{+} 3$. In $\mathrm{H}^{+} 2$ there was minor damage to its caudal pole.
$H^{+} A^{+}$group. The most complete description of this lesion appears in Zola-Morgan et al. (1989c). Removal of the hippocampal formation and amygdala was nearly complete in all four animals. In each case there was also significant bilateral damage to the perirhinal and parahippocampal cortex. In addition, at least some of the white matter located lateral to the amygdaloid complex was damaged bilaterally.

\section{Behavioral findings}

Delayed nonmatching to sample. The four groups differed in their ability to learn the basic task with a delay of $8 \sec (F[3,14]$ $=19.9, p<0.001)$. Figure $10 \mathrm{~A}$ shows that the normal group required 197 trials to reach learning criterion on the basic task, while the $\mathrm{H}^{+}$group required 540 trials, and the $\mathrm{H}^{+} \mathrm{A}^{+}$group required 790 trials. The ISC group required only 50 trials. Compared with the normal group, the $\mathrm{H}^{+}$and $\mathrm{H}^{+} \mathrm{A}^{+}$groups were impaired ( $p s<0.05$ ). The ISC group learned the basic task in fewer trials than any other group $(p<0.05)$.

Figure $10 B$ shows performance as the delay was increased from $8 \mathrm{sec}$ to $10 \mathrm{~min}$. Table 1 shows the scores for individual animals. An ANOVA involving all four groups and three delays (15 sec, $60 \mathrm{sec}$, and $10 \mathrm{~min}$ ) revealed a significant effect of group $(F[3,17]=28.3, p<0.0001)$ and delay $(F[2,36]=57.1, p<$ $0.0001)$, but no interaction $(F[6,36]=1.5)$. Separate comparisons based on each group's scores averaged across the three delays ( $15 \mathrm{sec}, 60 \mathrm{sec}$, and $10 \mathrm{~min}$ ) revealed that the $\mathrm{ISC}, \mathrm{H}^{+}$, and $\mathrm{H}^{+} \mathrm{A}^{+}$groups were impaired relative to the normal group $(p<0.05)$. In addition, the $\mathrm{H}^{+} \mathrm{A}^{+}$group performed significantly worse than the ISC and $\mathrm{H}^{+}$groups $(p<0.01)$. Across the three delays, the ISC group ( $77 \%$ correct) performed about the same as the $\mathrm{H}^{+}$group ( $78 \%$ correct). All the lesion groups were also impaired when the scores at the longest $(10 \mathrm{~min})$ delay were considered separately $(t>2.90, p<0.05)$.

Pattern discrimination. The number of trials required to learn the two pattern discrimination problems were averaged together for each monkey (Fig. 11). Monkey N5 was unable to learn either problem, and monkey N7 was unable to learn the first problem. In these cases, testing was discontinued after 1000 trials, and the animal was assigned a score of 1000 for that 


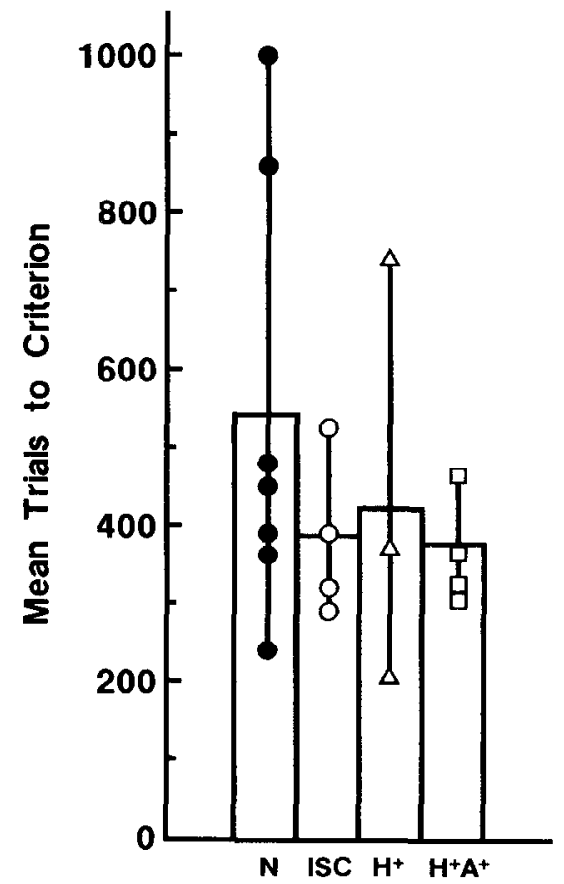

Figure 11. Average scores on two pattern discrimination tasks by normal monkeys $(N)$, monkeys that underwent 15 min of cerebral ischemia (ISC), monkeys with lesions of the hippocampal formation $\left(H^{+}\right)$, and monkeys with conjoint lesions of the hippocampus and amygdala that also damaged the adjacent cortical regions $\left(H^{+} A^{+}\right)$. Symbols show scores for individual monkeys.

problem. All four groups performed similarly $(F[3,17]<1.0)$. The results were the same when the two normal animals who had difficulty learning were excluded.

Delayed retention of object discrimination. The data for all
Table 1. Delayed nonmatching to sample

\begin{tabular}{|c|c|c|c|c|c|}
\hline \multirow[b]{2}{*}{ Subject $^{a}$} & \multirow{2}{*}{$\begin{array}{l}\text { Trials to } \\
\text { criterion }\end{array}$} & \multicolumn{4}{|c|}{ Delays } \\
\hline & & $8 \mathrm{sec}$ & $15 \mathrm{sec}$ & $60 \mathrm{sec}$ & $10 \mathrm{~min}$ \\
\hline \multicolumn{6}{|l|}{ Group N } \\
\hline 1 & 180 & 90 & 95 & 86 & 80 \\
\hline 2 & 440 & 91 & 91 & 90 & 64 \\
\hline 3 & 220 & 90 & 91 & 85 & 76 \\
\hline 4 & 120 & 91 & 98 & 93 & 83 \\
\hline 5 & 180 & 90 & 95 & 85 & 80 \\
\hline 6 & 160 & 90 & 96 & 97 & 80 \\
\hline 7 & 80 & 90 & 92 & 89 & 92 \\
\hline Mean & 197 & 90 & 94 & 89 & 79 \\
\hline \multicolumn{6}{|c|}{ ISC group } \\
\hline 1 & 80 & 90 & 95 & 95 & 66 \\
\hline 2 & 20 & 92 & 82 & 78 & 52 \\
\hline 3 & 80 & 92 & 87 & 90 & 56 \\
\hline 4 & 20 & 91 & 75 & 72 & 70 \\
\hline Mean & 50 & 91 & 85 & 84 & 61 \\
\hline \multicolumn{6}{|c|}{$\mathrm{H}^{+}$group } \\
\hline 1 & 260 & 91 & 85 & 78 & 60 \\
\hline 2 & 520 & 92 & 90 & 78 & 64 \\
\hline 3 & 840 & 91 & 88 & 91 & 68 \\
\hline Mean & 540 & 91 & 88 & 82 & 64 \\
\hline \multicolumn{6}{|c|}{$\mathrm{H}^{+} \mathbf{A}^{+}$group } \\
\hline 1 & 1000 & 90 & 71 & 62 & 54 \\
\hline 2 & 740 & 91 & 64 & 68 & 44 \\
\hline 3 & 800 & 90 & 65 & 58 & 51 \\
\hline 4 & 620 & 91 & 70 & 70 & 58 \\
\hline Mean & 790 & 91 & 68 & 65 & 52 \\
\hline
\end{tabular}

${ }^{a} \mathrm{~N}$, normal monkeys; ISC, monkeys that underwent 15 min of cerebral ischemia; $\mathrm{H}^{+}$, monkeys with lesions of the hippocampal formation that included the parahippocampal cortex; $\mathrm{H}^{+} \mathrm{A}^{+}$, monkeys with conjoint lesions of the hippocampus and amygdala that also damaged the adjacent cortical regions.
Figure 12. Average daily performance on four object discrimination tasks by normal monkeys $(N)$, monkeys that underwent 15 min of cerebral ischemia (ISC), monkeys with lesions of the hippocampal formation $\left(H^{+}\right)$, and monkeys with conjoint lesions of the hippocampus and amygdala that also damaged the adjacent cortical regions $\left(H^{+} A^{+}\right)$. Symbols show scores for individual monkeys. *, Day 1 , indicates three animals who obtained a score of $75 \%$; *, Day 4 , indicates four animals who obtained a score of $93 \%$.

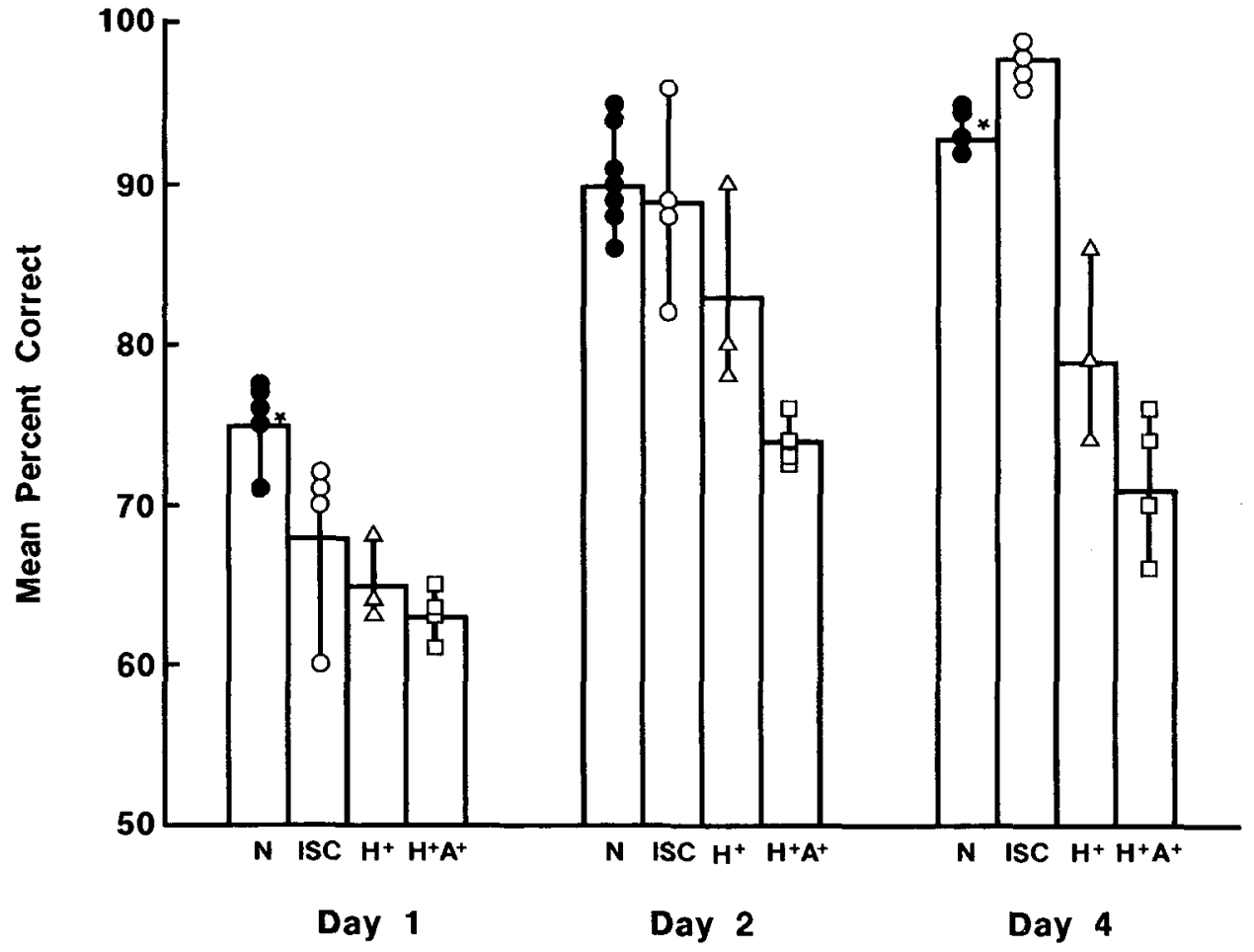


Table 2. Performance on tasks sensitive to amnesia

\begin{tabular}{|c|c|c|c|c|}
\hline Subject ${ }^{a}$ & $\begin{array}{l}\text { Delayed } \\
\text { nonmatching }\end{array}$ & $\begin{array}{l}\text { Object } \\
\text { retention }\end{array}$ & $\begin{array}{l}\text { Concurrent } \\
\text { discrimina- } \\
\text { tion }\end{array}$ & $\begin{array}{l}\text { Delayed } \\
\text { nonmatching } \\
\text { retest }^{b}\end{array}$ \\
\hline \multicolumn{5}{|l|}{ Group N } \\
\hline 1 & 80 & 88 & 240 & 66 \\
\hline 2 & 64 & 88 & 720 & 76 \\
\hline 3 & 76 & 85 & 640 & 82 \\
\hline 4 & 83 & 86 & 240 & 82 \\
\hline 5 & 80 & 85 & 360 & 70 \\
\hline 6 & 80 & 86 & 480 & 86 \\
\hline 7 & 92 & 87 & 600 & 80 \\
\hline Mean & 79 & 86 & 469 & 77 \\
\hline \multicolumn{5}{|c|}{ ISC group } \\
\hline 1 & 66 & 81 & 560 & 72 \\
\hline 2 & 52 & 89 & 280 & 62 \\
\hline 3 & 56 & 84 & 720 & 66 \\
\hline 4 & 70 & 86 & 320 & 70 \\
\hline Mean & 61 & 85 & 470 & 68 \\
\hline \multicolumn{5}{|l|}{$\mathrm{H}^{+}$group } \\
\hline 1 & 60 & 75 & 760 & 69 \\
\hline 2 & 64 & 72 & 720 & 60 \\
\hline 3 & 68 & 80 & 880 & 60 \\
\hline Mean & 64 & 76 & 787 & 63 \\
\hline \multicolumn{5}{|c|}{$\mathrm{H}^{+} \mathrm{A}^{+}$group } \\
\hline 1 & 54 & 71 & 960 & \\
\hline 2 & 44 & 69 & 1160 & \\
\hline 3 & 51 & 71 & 760 & \\
\hline 4 & 58 & 67 & 1520 & \\
\hline Mean & 52 & 70 & 1100 & \\
\hline
\end{tabular}

The score for the delayed nonmatching task is the percentage correct score for the 10 min delay. The score for the object retention task is the percentage correct score averaged across three test days. For concurrent discrimination, the score is the number of trials required to reach the learning criterion. The score for the delayed nonmatching retest is the percentage correct score for the $10 \mathrm{~min}$ delay. a $\mathrm{N}$, normal monkeys; ISC, monkeys that underwent $15 \mathrm{~min}$ of cerebral ischemia; $\mathrm{H}^{+}$, monkeys with lesions of the hippocampal formation that included the parahippocampal cortex; $\mathrm{H}^{+} \mathrm{A}^{+}$, monkeys with conjoint lesions of the hippocampus and amygdala that also damaged the adjacent cortical regions.

${ }^{b} \mathrm{H}^{+} \mathrm{A}^{+}$animals were not retested on delayed nonmatching to sample.

four discriminations were averaged together, and the mean percentage correct score was calculated for each day of testing (Fig. 12). Scores for individual animals appear in Table 2. A twoway ANOVA involving all four groups revealed an overall group effect $(F[3,17]=51.2, p<0.0001)$, an effect across days $(F[2,36]$ $=158.5, p<0.0001)$, and a group $\times$ day interaction $(F[6,36]$ $=8.2, p<0.0001)$. Separate comparisons between groups revealed that the ISC, $\mathrm{H}^{+}$, and $\mathrm{H}^{+} \mathrm{A}^{+}$groups were all impaired on day 1 of the object discrimination task $(p<0.001)$. Performance on day 1 was similar for the ISC, $\mathrm{H}^{+}$, and $\mathrm{H}^{+} \mathrm{A}^{+}$monkeys $(68 \%$, $65 \%$, and $63 \%$ correct, respectively; $p>0.10$ ). Comparisons of overall performance, averaged across all $3 \mathrm{~d}$ (Table 2), showed that the monkeys with ISC lesions performed similarly to normal monkeys ( $\mathrm{N}$ vs. ISC: $t[9]=1.03, p>0.05$ ), whereas the $\mathrm{H}^{+}$and $\mathrm{H}^{+} \mathrm{A}^{+}$groups were impaired relative to both the $\mathrm{N}$ and ISC groups (all $t \mathrm{~s}>3.19, p<0.05$ ). Finally, the $\mathrm{H}^{+}$group performed better than the $\mathrm{H}^{+} \mathrm{A}^{+}$group $(p<0.05)$.

Concurrent discrimination. Scores for each group are presented in Figure 13. Scores for individual animals appear in Table 2. An ANOVA revealed a significant group effect $(F[3,17]$

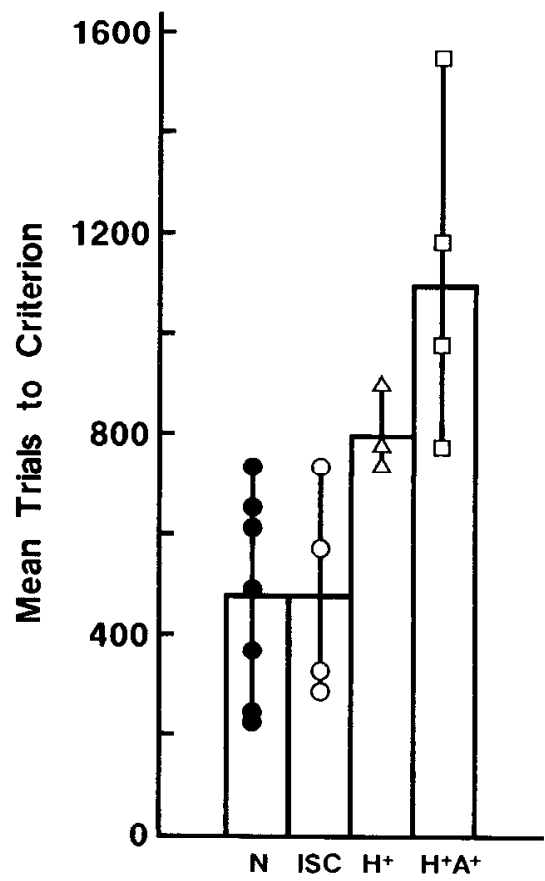

Figure 13. Performance on the eight-pair concurrent task by normal monkeys $(N)$, monkeys that underwent $15 \mathrm{~min}$ of cerebral ischemia (ISC), monkeys with lesions of the hippocampal formation $\left(\mathrm{H}^{+}\right)$, and monkeys with conjoint lesions of the hippocampus and amygdala that also damaged the adjacent cortical regions $\left(H^{+} A^{+}\right)$. Symbols show scores for individual monkeys.

$=8.3, p<0.01)$. Further comparisons between groups showed that both the $\mathrm{H}^{+}$and $\mathrm{H}^{+} \mathrm{A}^{+}$groups were impaired $(p<0.05)$, but that the ISC group performed normally. In addition, the ISC group performed better than both the $\mathrm{H}^{+}$group $(p<0.06)$ and the $\mathrm{H}^{+} \mathrm{A}^{+}$group $(p<0.05)$. The $\mathrm{H}^{+}$and $\mathrm{H}^{+} \mathrm{A}^{+}$groups performed similarly $(p>0.10)$.

Delayed nonmatching to sample retest. The interval between the first and second administrations of delayed nonmatching to sample was 6-9 months for the normal and the ISC groups and 41 months for the $\mathrm{H}^{+}$group (Zola-Morgan et al., 1989a). Monkeys in the $\mathrm{H}^{+} \mathrm{A}^{+}$group were not retested on the standard nonmatching task. However, at 1.5 years after surgery they were impaired on a modified version of this task in which a distracting event was introduced during some of the delay trials (ZolaMorgan and Squire, 1985). Figure $14 A$ shows the mean number of trials required to reach learning criterion on the basic $(8 \mathrm{sec})$ task. Compared with normal monkeys, the monkeys in the ISC group were impaired in their ability to relearn the basic task $[t(9)=2.38, p<0.05]$. None of the other pairwise comparisons between groups was significant $(p>0.10)$.

Figure $14 B$ shows performance as the delay was increased from $8 \mathrm{sec}$ to $10 \mathrm{~min}$. An ANOVA involving three groups and three delays $(15 \mathrm{sec}, 60 \mathrm{sec}$, and $10 \mathrm{~min})$ revealed a significant effect of delay $(F[2,28]=39.5, p<0.0001)$, no effect of group $(F[2,13]=3.1, p>0.05)$, and no group $\times$ delay interaction $(F[4,28]=2.29, p>0.05)$. Separate comparisons based on each group's average scores across the three delays $(15 \mathrm{sec}, 60 \mathrm{sec}$, and $10 \mathrm{~min})$ revealed that the ISC group $\left(82 \%\right.$ correct), the $\mathrm{H}^{+}$ group $(81 \%$ correct), and the normal group $(86 \%$ correct) performed similarly. At the longest (10 min) delay, however, both the ISC and $\mathrm{H}^{+}$groups were impaired (N vs. ISC: $t[9]=2.48$, $p<0.05 ; \mathrm{N}$ vs. $\mathrm{H}^{+}: t[6]=3.10, p<0.05$ ). The $\mathrm{H}^{+}$and ISC 
Figure 14. Performance on the retest of the delayed nonmatching to sample task by normal monkeys $(N)$, monkeys that underwent 15 min of cerebral ischemia (ISC), and monkeys with lesions of the hippocampal formation $\left(\mathrm{H}^{+}\right)$. The normal monkeys and the ISC monkeys were retested on the delayed nonmatching task 6-9 months after first testing. Monkeys in the $\mathrm{H}^{+}$group were retested 41 months after the first testing (ZolaMorgan et al., 1989b). The $\mathrm{H}^{+} \mathrm{A}^{+}$group was not retested on delayed nonmatching to sample. $A$, Initial learning of the task with a delay of $8 \mathrm{sec}$. Symbols show trials to critcrion for individual animals. * indicates five animals who obtained a score of 0 trials. $B$, Performance across delays for the same groups.
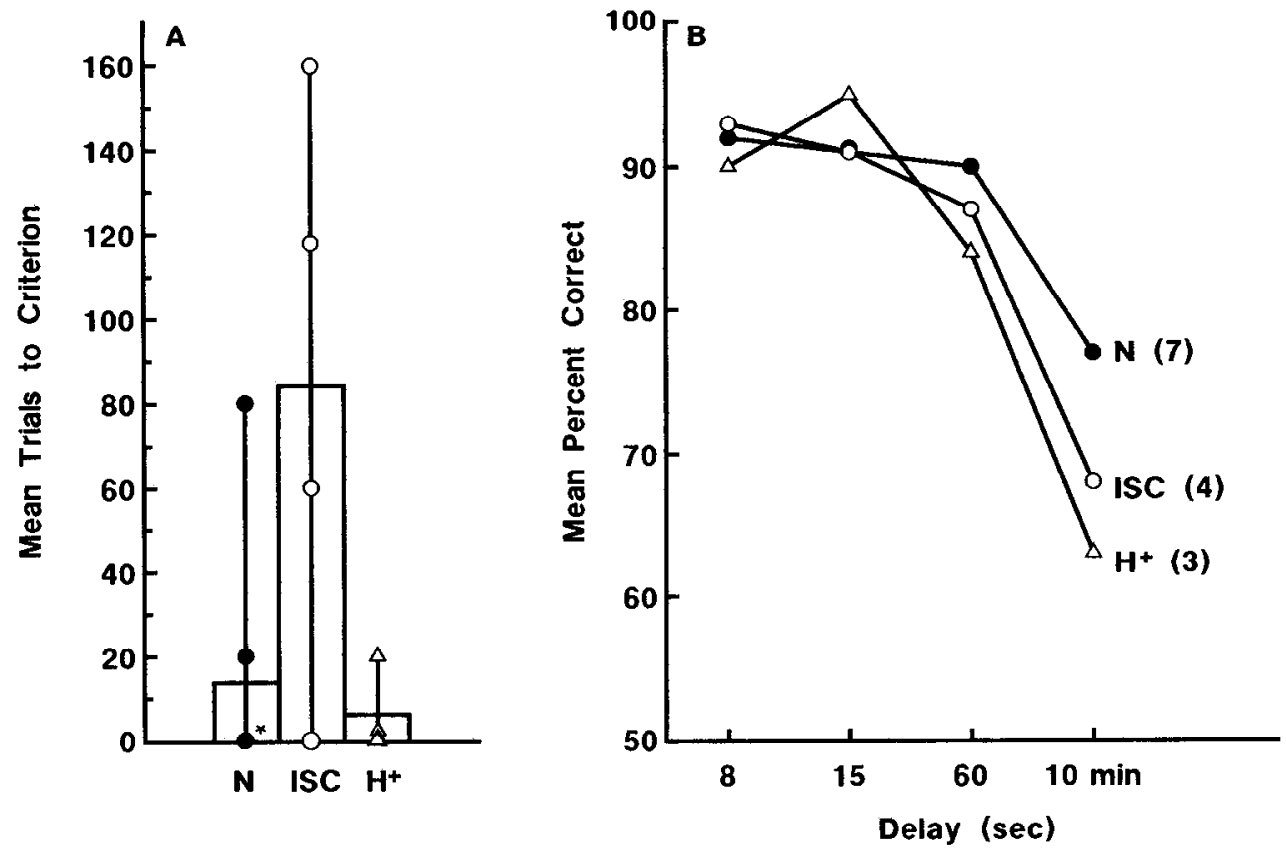

groups performed similarly $(63 \%$ vs. $68 \%$ correct, $t[5]=1.24$, $p>0.10$ ).

On this test, the normal group and the experimental groups performed about the same as they had at the earlier testing. The normal group scored $88 \%$ correct when the test was first given (averaged across the three longest delays) and scored $86 \%$ correct on the second test. The $\mathrm{H}^{+}$group scored $78 \%$ correct on the first test and $81 \%$ on the second test; the ISC group scored $77 \%$ correct on the first test and $82 \%$ on the second test ( $p s>0.10$ ). A similar pattern was seen at the longest delay $(10 \mathrm{~min}$; for the $\mathrm{N}$ and $\mathrm{H}^{+}$groups, $p \mathrm{~s}>0.50$; for the ISC group, $p=0.07$ ).

Lifesaver. All monkeys learned the Lifesaver task at a similar rate. A two-way ANOVA involving four groups and eight test days revealed a significant effect of session $(F[7,119]=27.8, p$ $<0.01$ ), indicating that performance improved across test days. However, there was no effect of group and no significant group $\times$ session interaction $(F \mathrm{~s}<1.0)$ (only three of the four $\mathrm{H}^{+} \mathrm{A}^{+}$ monkeys were administered the Lifesaver task). One month after the final session of initial learning, all groups also performed equivalently $(F<1.0)$.

\section{Discussion}

There were two main findings. First, cerebral ischemia in the monkey produced selective and consistent bilateral cell loss in the hippocampus and the dentate gyrus. Second, although hippocampal damage in the ISC monkeys was incomplete, the damage was nevertheless sufficient to produce long-lasting memory impairment.

Neuropathological findings. Ischemia resulted in selective bilateral damage to the hippocampus in all four ISC monkeys. Each monkey sustained significant loss of pyramidal cells in the CA1 and CA2 fields of the hippocampus and loss of SS-immunoreactive cells in the hilar region of the dentate gyrus. Cell loss occurred bilaterally throughout the rostrocaudal extent of the hippocampus but was greater in its caudal portion (Figs. 4, 6 ). Greater cell loss in the septal (caudal) portion of the hippocampus has also been described in rats following ischemia (Smith et al., 1984; Ashton et al., 1989; Auer et al., 1989).
With the exception of patchy loss of cerebellar Purkinje cells, no significant damage was detected in areas outside the hippocampus, including adjacent cortical regions and other regions that have been implicated in memory function. These findings are consistent with the pattern of neuronal damage reported in the rat following transient forebrain ischemia: extensive loss of CA1 neurons throughout the hippocampus, loss of CA2 neurons, and loss of SS-immunoreactive neurons in the hilar region of the dentate gyrus (Smith et al., 1984; Johansen et al., 1987; Ashton et al., 1989; Auer et al., 1989; Davis and Volpe, 1990; Grimaldi et al., 1990). In studies of post-mortem brain tissue from patients with epilepsy, the CA2 field in the hippocampus has been sometimes described as an area resistant to damage (Adams et al., 1984). Until now, there have been no systematic studies of the effects of ischemia on this region either in humans or in monkcys.

It has been reported in rats that loss of SS-immunoreactive neurons in the dentate gyrus precedes CAl pyramidal cell loss (Johansen and Diemer, 1986). Subsequently, it was proposed that the loss of SS-immunoreactive neurons may induce hyperactivity in the CA1 neurons and thereby promote cell death (Johansen et al., 1987). In the present study, however, the extent of cell loss in the CA fields did not correspond to the extent of loss of SS-immunoreactive cells. Thus, monkeys ISC1 and ISC3 both had greater loss of SS-positive cells than monkey ISC2, but monkey ISC2 had the greatest loss of cells in the CA fields. Accordingly, although the present study provides no information about the time course of cell loss in these two regions of the hippocampus, cell loss in the CA fields appears to be independent of cell loss in the dentate gyrus.

Memory impairment. The ISC monkeys were impaired on the delayed nonmatching to sample task and also exhibited impairment when retested at the same delay intervals approximately 8 months later (Figs. 10, 14). On the object discrimination task, the ISC monkeys were impaired only on the first day of testing, and they were unimpaired on the eight-pair concurrent discrimination task (Table 2; Figs. 12, 13). Finally, the ISC monkeys learned the two pattern discrimination problems 
normally, and they were normal at learning and retaining the Lifesaver motor skill task. These behavioral findings indicate that even partial damage to the hippocampus produces detectable memory impairment on tasks sensitive to human amnesia. Similar findings have been reported in rats (Volpe et al., 1984; Grotta et al., 1988; Ordy et al., 1988; Auer et al., 1989; Voll et al., 1989; Davis and Volpe, 1990). Accordingly, the findings in rats, monkeys, and humans (case RB) are in agreement that ischemic damage to the hippocampus can produce significant and long-lasting memory impairment.

The severity of memory impairment following ischemia. The memory impairment of ISC animals was less severe overall than the impairment associated with surgical lesions of the hippocampal formation (the $\mathrm{H}^{+}$lesion) and much less severe than the momory impairment associated with $\mathrm{II}^{+} \mathrm{A}^{+}$lesions. First, on the delay portions of the nonmatching to sample task, monkeys with ischemic lesions were impaired to ahout the same degree as monkeys with $\mathrm{H}^{+}$lesions and were less impaired than monkeys with $\mathrm{H}^{+} \mathrm{A}^{+}$lesions (Table 1; Figs. 10, 14). On the object retention and eight-pair concurrent discrimination tasks, ISC monkeys performed better than monkeys with either $\mathrm{H}^{+}$or $\mathrm{H}^{+} \mathrm{A}^{+}$ lesions (Table 2; Figs. 12, 13).

The $\mathrm{H}^{+}$lesion involved nearly all of the hippocampus bilaterally as well as the parahippocampal cortex and posterior entorhinal cortex. If significant undetected damage had occurred in the ISC monkeys in these two cortical areas or in other areas important for memory function, one would expect the memory impairment in the ISC monkeys to have approximated more closely or to have exceeded the memory impairment associated with the $\mathrm{H}^{+}$lesion. However, the ischemic lesion produced significantly less memory impairment overall than the $\mathrm{H}^{+}$lesion.

It is also useful to compare the findings from the ISC group to findings from monkeys with bilateral lesions limited to the hippocampus (the H lesion; Clower et al., 1991; Squire and ZolaMorgan, 1991). The $\mathrm{H}$ lesion was produced using stereotaxic coordinates established with the aid of preoperative MR imaging (Alvarez-Royo et al., 1991). Overall, the ISC group performed rather similarly to the $\mathbf{H}$ group. Both groups were similarly impaired on the delayed nonmatching to sample task when it was first administered (performance at 10 min delay: ISC group, $61 \%$ correct; $H$ group, $68 \%$ correct). They also performed similarly on the object retention task (mean percentage correct averaged across $3 \mathrm{~d}$ : ISC groups, $85 \%$ correct; $\mathrm{H}$ group, $85 \%$ correct) and the eight-pair concurrent discrimination task (trials to criterion: ISC, 470 trials; H, 350 trials). Finally, both groups performed similarly when the delayed nonmatching to sample task was administered a second time (performance at $10 \mathrm{~min}$ delay: ISC group, $68 \%$ correct; $H$ group, $70 \%$ correct). In summary, monkeys in the ISC group were less impaired overall than monkeys with $\mathrm{H}^{+}$lesions, and they exhibited about the same level of impairment as monkeys with surgical lesions of the hippocampus. It seems unlikely, therefore, that the ISC monkeys had widespread neuropathological change affecting memory that was not detected by histological analysis. Indeed, the pathology in the ischemic animals must involve less tissue in structures related to memory function than was involved in the $\mathrm{H}^{+}$lesion. At the same time, we cannot fully exclude the possibility that some neuropathological change has occurred that was not detected.

In a recent report, ischemic damage was induced in a group of six rhesus monkeys by nonreversible occlusion of the posterior cerebral artery (Bachevalier and Mishkin, 1989). Three of the six monkeys were described as having bilateral damage involving the CA1 and CA2 fields of the hippocampus and, on average, damage to $20-55 \%$ of the hippocampal formation. Yet these three monkeys exhibited a somewhat greater impairment on the delayed nonmatching to sample task than monkeys who sustained surgical removal of the hippocampal formation. Bachevalier and Mishkin (1989) considered three possible explanations for the unexpected finding that ischemic damage, apparently involving only a portion of the hippocampal formation, resulted in greater memory impairment than the larger lesion produced by surgery.

One possibility was that partial damage to the hippocampus has more severe behavioral consequences than complete removal of the hippocampus. This idea is not supported by a recent study in rats. Davis and Volpe (1990) found that damagc to primarily the CA1 region of the hippocampus, caused by a low concentration of ibotenic acid, produced less memory impairment than a higher concentration that damaged both the CAl region and other regions of the hippocampus more extensively. Other findings suggested that extensive damage to the CAl region produced by cerebral ischemia was as disruptive to memory function as ibotenic lesions that produced similar damage in the CAl region as well as additional damage in the hippocampus. Thus, partial hippocampal lesions produced either less memory impairment or similar memory impairment, in comparison to larger hippocampal lesions, but partial lesions did not produce more memory impairment than larger lesions.

Second, neuronal changes contributing to memory impairment might have occurred outside the hippocampus that were not detectable by conventional histological analyses. The findings from the present study, however, argue against this possibility. As discussed above, the level of memory impairment observed in the ISC group was about what would have been expected given the amount of hippocampal pathology.

A third possibility was that the severe memory impairment in the ischemic monkeys might have been caused by histologically verified damage outside the hippocampal region. In each of the three cases, additional ischemic lesions were evident in various brain regions (e.g., the ventrolateral thalamus and the lateral geniculate), but this damage was not viewed as sufficient to explain the severe memory impairment, because it was not found in brain regions known to participate in memory functions.

Although it is not entirely clear how to explain these results, an additional possibility is that the standard histological methods used in this study overlooked ischemic damage in areas of the hippocampal formation and adjacent cortex that werc not damaged in the surgical lesion. Perhaps a detailed comparison of the percentage of damage to the hippocampal formation and adjacent cortex in both the surgical group and the ischemic group would clarify these puzzling findings.

The findings reported here make several important points. First, the findings with the ISC monkeys show that even incomplete damage to the hippocampus is sufficient to produce detectable memory impairment in monkeys, just as it can in humans (case RB) and in rats (Davis and Volpe, 1990). These findings therefore support the long-standing idea that the hippocampus itself is important for memory and that damage limited to the hippocampus is sufficient to cause significant memory impairment. Second, the ISC monkeys demonstrated less severe memory impairment overall than the $\mathrm{H}^{+}$surgical lesion and about the same level of impairment as the $H$ surgical lesions. 
Accordingly, it is implausible that the ischemic animals (and by analogy the ischemic patient RB) had widespread pathological change affecting memory that was not subsequently detected by histological examination. Finally, the finding that significant and long-lasting memory impairment can be detected in behavioral tasks given to monkeys that have sustained partial damage to the hippocampus contrasts sharply with the absence of detectable memory impairment following virtually complete lesions of the amygdala (Zola-Morgan et al., 1989b).

\section{References}

Adams JH, Corsellis JAN, Duchen LW (1984) Greenfield's neuropathology, 4th ed, p 928. New York: Wiley.

Alvarez-Royo P, Clower RP, Zola-Morgan S, Squirc LR (1991) Stcreotaxic lesions of the hippocampus in monkeys: determination of surgical coordinates and analysis of lesions using magnetic resonance imaging. J Neurosci Methods 38:223-232.

Amaral D, Insausti R, Zola-Morgan S, Squire LR, Suzuki WA (1990) The perirhinal and parahippocampal cortices and medial temporal lobe memory function. In: Vision, memory, and the temporal lobe (Iwai E, Mishkin M, eds.), pp 149-160. New York: Elsevier.

Ashton D, Van Reempts J, Haseldonckx M, Willems R (1989) Dorsalventral gradient in vulnerability of CA1 hippocampus to ischemia: a combined histological and electrophysiological study. Brain Res 487: 368-372.

Auer RN, Jensen ML, Whishaw IQ (1989) Neurobehavioral deficit due to ischemic brain damage limited to half of the CA1 sector of the hippocampus. J Neurosci 9:1641-1647.

Bachevalier J, Mishkin M (1989) Mnemonic and neuropathological effects of occluding the posterior cerebral artery in Macaca mulatta. Neuropsychologia 27:83-105.

Bakst I, Morrison JH, Amaral DG (1985) The distribution of somatostatin-like immunoreactivity in the monkey hippocampal formation. J Comp Neurol 236:423-442.

Benoit R, Ling N, Alford B, Guillemin R (1982) Seven peptides derived from pro-somatostatin in rat brain. Biochem Biophys Res Commun 107:944-950.

Clower RP, Alvarez-Royo A, Zola-Morgan S, Squire LR (1991) Recognition memory impairment in monkeys with selective hippocampal lesions. Soc Neurosci Abstr 17:338.

Davis HP, Volpe BT (1990) Memory performance after ischemic or neurotoxic damage of the hippocampus. In: The biology of memory (Squire LR, Lindenlaub E, eds), pp 477-504. Stuttgart: Schattauer.

Fleischer JE, Lanier WL, Milde JH, Michenfelder JD (1987) Lidoflazine does not improve neurologic outcome when administered after complete cerebral ischemia in primates. $\mathbf{J}$ Cereb Blood Flow Metab $7: 366-371$

Gallyas F (1979) Silver staining of myelin by means of physical development. Neurol Res 1:203-209.

Grimaldi R, Zoli M, Agnati LF, Ferraguti F, Fuxe K, Toffano G, Zini I (1990) Effects of transient forebrain ischemia on peptidergic neurons and astroglial cells: evidence for recovery of peptide immunoreactivities in neocortex and striatum but not hippocampal formation. Exp Brain Res 82:123-136.

Grotta JC, Pettigrew LC, Rosenbaum D, Reid C, Rhoades H, McCandless D (1988) Efficacy and mechanism of action of a calcium blocker after global cerebral ischemia in rats. Stroke 19:447-454.

Harlow H, Bromer JA (1938) A test-apparatus for monkeys. Psychol Kev 19:434-438.

Hartley LH, Roger R, Nicolosi RJ, Hartley T (1984) Blood pressure values in Macaca fascicularis. J Med Primatol 13:183-189.

Johansen FF, Diemer NH (1986) No loss of GABAergic interneurons in the rat hippocampal formation after $20 \mathrm{~min}$ of transient cerebral ischemia: an immunohistochemical investigation of L-glutamate decarboxylase. Xth International Congress of Neuropathology, Stockholm, Sweden (Abst) 420:209.

Johansen FF, Zimmer J, Diemer NH (1987) Early loss of somatostatin neurons in dentate hilus after cerebral ischemia in the rat precedes CA-1 pyramidal cell loss. Acta Neuropathol (Berl) 73:110-114.
Mahut H, 7ola-Morgan S, Moss M (1982) Hippocampal resections impair associative learning and recognition memory in the monkey. J Neurosci 2:1214-1229.

Mishkin M (1978) Memory in monkeys severely impaired by combined but not separate removal of the amygdala and hippocampus. Nature 273:297-298.

Nadler JV, Evenson DA (1983) Use of excitatory amino acids to make axon-sparing lesions of hypothalamus. Methods Enzymol 103:393400 .

Nemoto EM, Bleyaert AL, Stezoski SW, Moossy J, Rao GR, Safar P (1977) Global brain ischemia: a reproducible monkey model. Stroke $8: 558-564$.

Ordy JM, Thomas GJ, Volpe BT, Dunlap WP, Colombo PM (1988) An animal model of human-type memory loss based on aging, lesion, forebrain ischemia, and drug studies with the rat. Neurobiol Aging 9:667-683

Pitkanen A, Amaral DG (1991) Demonstration of projections from the lateral nucleus to the basal nucleus of the amygdala: a PH $\mathrm{P}-\mathrm{L}$ study in the monkey. Exp Brain Res 83:465-470.

Smith M-L, Auer RN, Siesjo BK (1984) The density and distribution of ischemic brain injury in the rat after 2-10 minutes of forebrain ischemia. Acta Neuropathol (Berl) 64:319-332.

Squire LR, Zola-Morgan S (1991) The medial temporal lobe memory system. Science 253:1380-1386.

Steen PA, Gisvold SE, Milde JH, Newberg LA, Scheithauer BW, Lanier WL, Michenfelder JD (1985) Nimodipine improves outcome when given after complete cerebral ischemia in primates. Anesthesiology $62: 406-414$

Szabo J, Cowan WM (1984) A stereotaxic atlas of the brain of the cynomolgus monkey (Macaca fascicularis). J Comp Neurol 222:265300.

Victor M, Agamanolis D (1990) Amncsia duc to lcsions confined to the hippocampus: a clinical-pathologic study. J Cogn Neurosci 2:246257

Voll CL, Whishaw IQ, Auer RN (1989) Postischemic insulin reduces spatial learning deficit following transient forebrain ischemia in rats. Stroke 20:646-651

Volpe BT, Pulsinelli WA, Tribuna J, Davis HP (1984) Behavioral performance of rats following transient forebrain ischemia. Stroke 15: $558-562$.

von Bonin G, Bailey P (1947) The neocortex of Macaca mulatta. Urbana, IL: University of Illinois.

Zola-Morgan S, Squire LR (1984) Preserved learning in monkeys with medial temporal lesions: sparing of motor and cognitive skills. J Neurosci 4:1072-1085.

Zola-Morgan S, Squire LR (1985) Mcdial tcmporal lesions in monkcys impair memory on a variety of tasks sensitive to human amnesia. Behav Neurosci 99:22-34.

Zola-Morgan S, Squire LR (1986) Memory impairment in monkeys following lesions of the hippocampus. Behav Neurosci 100:165-170.

Zola-Morgan S, Squire LR, Mishkin M (1982) The neuroanatomy of amnesia: amygdala-hippocampus versus temporal stem. Science 218: $1337-1339$.

Zola-Morgan S, Squire LR, Amaral DG (1986) Human amnesia and the medial temporal region: enduring memory impairment following a bilateral lesion limited to field CAl of the hippocampus. J Neurosci 6:2950-2967.

Zola-Morgan S, Squire LR, Amaral DG (1989a) Lesions of the hippocampal formation but not lesions of the fornix or the mammillary nuclei produce long-lasting memory impairment in monkeys. J Neurosci 9:897-912.

Zola-Morgan S, Squire LR, Amaral DG (1989b) Lesions of the amygdala that spare adjacent cortical regions do not impair memory or exacerbate the impairment following lesions of the hippocampal formation. J Neurosci 9:1922-1936.

Zola-Morgan S, Squire LR, Amaral DG, Suzuki W (1989c) Lesions of perirhinal and parahippocampal cortex that spare the amygdala and hippocampal formation produce severe memory impairment. J Neurosci 9:4355-4370.

Zola-Morgan S, Squire LR, Alvarez-Royo P, Clower RP (1991) Independence of memory functions and emotional behavior: separate contributions of the hippocampal formation and the amygdala. Hippocampus 1:207-220. 